\title{
A review on renewable energy transition in Australia: an updated depiction
}

\author{
Hong Xian Li ${ }^{a}$, Edwards ${ }^{b}$, D.J., M. Reza Hosseini ${ }^{a, *}$, Glenn P. Costin ${ }^{a}$ \\ a. School of Architecture and Built Environment, Deakin University, 1 Gheringhap Street, Geelong, \\ Victoria 3220, Australia. Email: hong.li@deakin.edu.au; reza.hosseini@deakin.edu.au; \\ g.costin@deakin.edu.au; \\ b. School of Engineering and the Built Environment, Birmingham City University, UK and \\ Department of Construction Management and Quantity Surveying, University of Johannesburg, \\ South Africa. Email: drdavidedwards@aol.com \\ *Corresponding author: M. Reza Hosseini \\ E-mail address: reza.hosseini@deakin.edu.au
}

\begin{abstract}
Despite the global context, only 6\% of Australia's total energy consumption was derived from renewables, while $86.3 \%$ of electricity was generated from fossil fuels. However, this trend has been disrupted by the recent decommissioning and closure of a fleet of ageing coal power plants given the country's international commitments to reduce fossil fuel emissions. Currently, Australia is at a crucial stage of its transition to renewable energy adoption. Against this prevailing contextual backdrop, this research paper presents a systematic review of contemporary literature to provide an updated depiction of renewable energy, related policy and the way ahead in the Australian context, from the perspectives of energy potential, utilisation and policy incentives. The research analysed a total of 117 documents using an interpretivist epistemological lens; emergent findings offer an evidence-based, lucid account of advancements in the renewable energy market. Some simple polynomial regression analysis is also conducted on secondary data obtained from the literature to predict trends in the electricity generated by different sources of renewable energy. The work also identifies several areas that require attention, viz: (1) the most recent time-varying feed-in tariffs (TV FiTs) which offer the innate potential to alter consumer attitudes toward power usage at peak times, thereby improving grid security; (2) the increasingly popular integration of waste-to-energy with other sources of renewable energy emerges as a viable complementary solution to meet energy demands; (3) the increasing utilisation of subsidised geothermal energy installations which are set to rise exponentially in the future; and (4) the use of Public Private Partnerships (PPP) for developing
\end{abstract}


renewable energy generation infrastructure and how this investment may facilitate the national transition to renewable energy adoption. This research contributes to the existing body of knowledge by raising awareness of the current state of renewable energy in Australia, along with proposing pragmatic recommendations for overcoming any challenges posed. As a comprehensive reference, this study provides practitioners and policymakers with thorough, reliable and collated information on Australia's current renewable energy position.

Keywords: solar energy; geothermal; hydropower; wind energy; waste-to-energy; Feed-in Tariffs (FiTs); Australia.

\section{Introduction}

The global economy's heavy reliance upon fossil fuels is under increasing threat by the dual challenges of supply security and climate change (Bahadori et al., 2013a). Worldwide oil and gas reserves are projected to be depleted by the middle of this century, followed by coal sixty years later (Musa et al., 2018). Scientific and public concerns about the insatiable consumption of fossil fuel and how this is inextricably linked to hastened global climate change have fuelled contemporary political debate and policy-making (Jordaan et al., 2017). Transitioning from fossil fuels to renewable energy is recognised internationally as being instrumental to tackling these aforementioned dual challenges (Chapman et al., 2018). For example, the EU has adopted a new climate and energy framework which includes delivering a minimum $27 \%$ share of renewable energy consumption by 2030 (European Commission, 2018). Despite this global context, only 6\% of Australia's total energy consumption was derived from renewables (DEE, 2018) whilst $86.3 \%$ of electricity was generated from fossil-based sources (Clean Energy Council, 2014). The heavy reliance upon coal (42.7\% black and $20.2 \%$ brown) to generate electricity has made Australia the highest emitter of greenhouse gases per capita globally (Hua et al., 2016). This places Australia at a crucial stage of seeking a pathway to fulfil its environmental obligations which include meeting the Paris Climate Agreement to reduce emissions generated in 2005 by a minimum of $26 \%$ by 2030 . 
Electricity generation is of particular importance for fulfilling either of the preferred trajectories. This is because traditional approaches to generate electricity (such as coal firing) yield significant environmental impact, and carbon and greenhouse gas reduction is likely to occur more rapidly in this sector (Goh et al., 2018). Recognising this, Australia's fleet of ageing coal-fired power plants are slowly being decommissioned - with 12 plants (or one third of total plants) closing since 2012 (Burke et al., 2018). Of the 22 that remain, at least eight more will be decommissioned by 2022 (Burke et al., 2018; Court, 2017). These closures have withdrawn 5,589 MW from the grid which is approximately equivalent to $50 \%$ of South Australia's generation capacity or all of its current gas-powered electricity generation (AER, 2017; Burke et al., 2018). Hence, Australia must urgently establish alternative modes of energy supply and formulate policies for transforming its energy sources to those that are cleaner

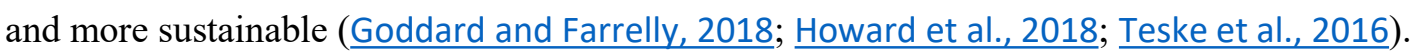

Renewable energy is deemed to be an effective solution for Australia to address these outstanding issues; hence, the renewable energy potential, renewable energy generation, and policies and incentives must be thoroughly studied and premeditated as a priority. Establishing strategies and formulating informed policies to facilitate the adoption of any innovative concept relies upon the identification and evaluation of factual evidence accrued for the utilisation of renewable energy, and awareness of a concept's current status within its immediate context (Slaughter, 2000; Wüstenhagen et al., 2007). As others have argued (e.g., Wüstenhagen et al. (2007)), transitioning to renewable energy follows this same principle of innovation adoption. Successful energy transition in Australia similarly relies on an appreciation of facts and an unambiguous cognisance of the country's renewable energy market. Yet, despite the global expansion of the renewable energy sector in recent years, the last study of Australia's power generation and consumption was conducted over five years ago (i.e., Bahadori et al. (2013a)) and no longer accurately reflects recent developments and challenges. Against this contextual backdrop, this article seeks to provide an updated depiction of renewable energy transition in Australia and in so doing, inform relevant government policy and practice. Furthermore, the study seeks to better position other researchers to formulate pertinent research questions relevant to both practice and policy for future research endeavours into the field. 


\section{Renewable energy}

Energy resources can be classified into three categories: 1) nuclear; 2) fossil fuels; and 3) renewable. Renewable energy is defined as energy obtained from non-depletable sources which create low levels of greenhouse gas emissions (Bilgili et al., 2015). However, the energy sector is subject to reciprocal interactions among a wide range of parallel and interacting forces of change (such as policy, technology and infrastructure). Comprehension of these forces is essential to enabling the renewable energy source transition of a nation (Jacobsson and Johnson, 2000; Wüstenhagen et al., 2007). Identifying and exploring these factors became a vibrant field of research post the 1973 global oil crisis and since then numerous studies have been undertaken (Hamawand et al., 2013; Jacobsson and Johnson, 2000).

A plethora of renewable energy exist, namely: solar, wind, geothermal, biomass, hydro, tidal, wave and ocean thermal energy - all of which are eminently available and adaptable to Australia's geophysical and political context (Kazem, 2011). Successfully exploiting these renewable energy options relies heavily upon the development of technology capable of harvesting such resources (Carbajo and Cabeza, 2018; Masini and Menichetti, 2012). For example, the power to gas (P2G), which constitutes a means of producing advanced renewable gaseous transport fuel, relies upon the extraction of hydrogen from water by means of electrolysis. This technology per se is novel, continually evolving and able to coalesce with other developing technologies such as biogas mixtures (Rahman et al., 2019a; McDonagh et al., 2018; Román-Leshkov et al., 2007).

For Australia, solar and wind generation of electrical power are the most logical and easily harvested of all renewable resources available. Solar is abundant and technological advancements in photovoltaics (PV) have significantly enhanced the effectiveness of solar power generation, whilst reducing installation cost (Dincer, 2011). Similarly, improvements in battery efficiency have radically improved the viability of this technological resource as a rapid back-up system to the grid in times of major generation failure $(\underline{A E M O}, 2018)$. Harnessing wind energy has a long history worldwide and is supported by mature technology and policy incentives (Kaldellis and Zafirakis, 2011); again, enhanced efficiency and capability of battery storage systems have furthered the advancement of this resource 
as a viable and reliable alternative power source. As an ancient technology, hydropower is being challenged by climate change and other environmental concerns. One review on international hydropower development set amidst the context of climate change, policy and the Water-Energy-Food nexus, concluded that all three factors must be carefully considered in policy and planning when shaping the future of hydropower as a genuinely sustainable resource (Zhang et al., 2017). Geothermal energy (alternatively known as earth-derived heat) remains an underutilised resource in Australia, despite it being the oldest of the renewable energy sources available. Globally, conventional geothermal systems use high heat flows from shallow magma near volcanically active regions. Such magma activity is not known in Australia thus, unconventional geothermal systems are deployed which derive heat from radiogenic reactions conducted from the Earth's mantle. Although Australia's identified geothermal potential (through accessing temperatures of $150-200^{\circ} \mathrm{C}$ at maximum depths of $5 \mathrm{~km}$ ) is 25,000 times the nation's annual primary energy consumption, only one electrical power generation plant is currently in use (Geoscience Australia, 2018b). Even direct-use technologies (e.g. hydronic floor heating or warming of swimming pools) are few, with only 6 major projects being identified (Geoscience Australia, 2018b).

As previously discussed, renewable energy storage tools, such as solar or wind charged battery facilities, have instigated widespread applied research into the practical implementation of renewable energy (Berrada and Loudiyi, 2016). The recent establishment of mini-grids in small Australian communities, such as Yackandandah (Victoria), clearly identify this as an essential route towards $100 \%$ renewable electricity generation, energy sovereignty and retention of main grid connectivity (Bloch, 2017). Other research into energy storage and its association with demand response techniques for the stable operation of renewable energy micro-grids supports this position, concluding that accurate modelling is required to achieve successful large-scale implementation (Robert et al. (2018). However, the success of the South Australian Hornsdale Power Reserve Battery Energy Storage System (HPR) in providing Frequency Control Ancillary Services (FCAS) in a fraction of the time required for traditional systems (diesel generators for example) demonstrates strong potential: strong enough for a 
$140 \mathrm{MWh}$ (20 MWh larger than HPR) battery system to be under construction near Port Augusta in the same state $(\underline{A B C, 2018})$.

Although advanced technology offers feasibility for the utilisation of renewable energy (Tran and Smith, 2017), technology per se is insufficient to promote widespread uptake of these power generation sources. Rather, environmental activists, government policies and tangible economic incentives play an important role (Masini and Menichetti, 2012). However, such policies must be highly strategic in both design and application. For example, Petersen (2018) analysed Denmark's Strategic Energy Plans (SEP) in light of the applied regional policies of 17 Danish municipalities. Technical, physical, organisational and local socioeconomics were all identified as key influences and challenges upon the capacity of regions to apply the SEP to their local energy policy implementation. In response, Petersen (2018) produced a community-oriented taxonomy of implementation specifically designed to help facilitate regional policy development.

In several countries, including Australia, a common policy designed to drive uptake of renewables is the feed-in tariff (FiT). FiTs offer a financial incentive to adopt renewable electricity through higher infeed prices for power fed into the grid. This policy's effectiveness is discussed later in this paper.

\section{Research methods}

The overarching epistemological design used to investigate the prevailing renewable energy discourse employed an interpretivist study (Myers, 2013) of the body of knowledge (BoK) contained within extant literature; where both published 'academic' and 'professional practice' work constituted the units of analysis under investigation (cf.Castilla-Polo and Ruiz-Rodríguez, 2017). Hence, this study predominantly emphasises qualitative vis-à-vis quantitative data analysis and the importance of professional practice developments (originating from government, professional body and regulatory authorities publications). Albeit, simple polynomial regression analysis is conducted on secondary data obtained from the literature to predict trends in the electricity generated by different sources of renewable energy.

From an operational perspective, this BoK was analysed using a systematic literature review (which itself is located within a positivist paradigm) to summarise published materials acquired via a 
snowballing approach (Reim et al., 2015). A systematic literature review was undertaken because this research technique is strongly associated with evidence-based practice and provides a mechanism for determining knowledge gaps and/or providing directions for future research (Mölder, 2010). Three core thematic groupings of research enquiry were iteratively undertaken in a logical 'waterfall' sequence, namely: 1) renewable energy potential; 2) renewable energy generation; and 3) policies and incentives. The emergent findings were then used to inform the discussion and provide direction for future research investigations. To search these aforementioned thematic groupings, a two-tier iterative stage process was adopted. First, a manual literature review was conducted to search for the latest literature (2017-2019) contained within various sources, including academic databases, government agencies and industry websites. Keywords used included 'renewable energy', 'Australia', 'solar energy', 'wind energy', 'geothermal energy', 'hydropower energy', 'ocean energy' and 'bioenergy'. Second and based on the results of stage one, 'snowballing' was adopted to broaden the literature base by identifying other pertinent research that contributed to, and expanded the broader BoK. To achieve this objective, the authors and references cited in the literature gathered in stage one enabled a multiplicative effect to snowball the literature e.g. 40 papers cited in a single paper identified in phase one grew the literature base by 41 . Two iterations of snowballing were conducted to identify a total sample size that constituted several tens of thousands of articles - note that only the most relevant (in this case Australia), current (within the last five years) and important publications are cited in this paper. The overall research framework is illustrated in Fig. 1. Based on the systematic literature review, the most relevant literature is thoroughly analysed for the three pillars of investigation viz: renewable energy potential, renewable energy generation, and policies and incentives. Research findings emanating from this study include novel knowledge contributions in the areas of: (1) renewable energy integration and waste-to-energy, (2) implementation of Public Private Partnerships (PPP) for renewable energy infrastructure, (3) geothermal energy exploitation, and (4) time-varying feed-in tariffs (TV FiTs) verification. 


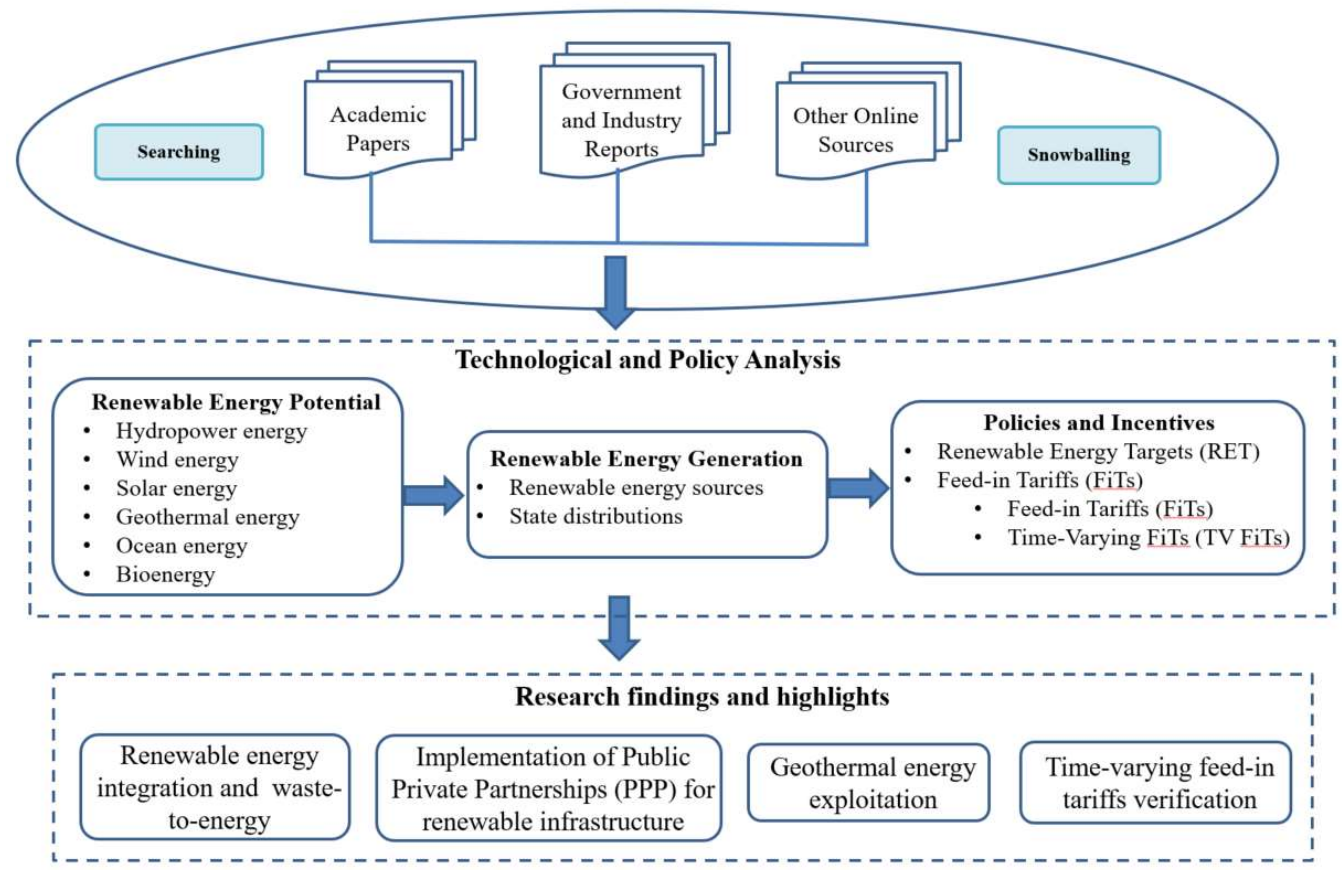

Fig. 1. Research Framework

\section{Renewable energy potential in Australia}

Australia is renowned for having favourable geophysical conditions to maximise its reliance upon widely distributed renewable energy sources, including an average solar radiation per $\mathrm{m}^{2}$ that is greater than any other land mass (Bahadori and Nwaoha, 2013; Trainer, 2012). Major renewable energy sources include hydropower, ocean energy, solar energy, wind energy, geothermal energy and bioenergy.

Hydropower was developed in Australia in the $19^{\text {th }}$ century within areas of high rainfall and elevation such as New South Wales and Tasmania. With an installed capacity of 8,790 MW, hydropower remains the largest renewable source of electrical energy generation in Australia, and the country is the world's fourth largest producer of hydropower (IHA, 2017). Yet, Australia's potential conventional hydropower capacity is actually fairly small due to a notable lack of viable on-river locations, variable annual rainfall, high temperatures and very high evaporation rates (Bahadori et al., 2013b). Despite these challenges, there remains strong potential for pumped hydroelectric energy storage systems (PHES) in Australia (Geoscience Australia, 2018c). In this scenario, excess power from wind or solar generation is used to pump water to header dams which effectively act as battery reserves to be 
released through downstream electricity plants in times of peak demand or main generation failure i.e., a potential backup Frequency Control Ancillary Services (FCAS) to support conventional battery systems (hu, 2018).

Australia also has significant ocean renewable energy potential from ocean waves, tidal, thermal and ocean currents (Behrens et al., 2012). The first wave-power patent was filed in Australia in 1909, with increasing government investment and private venture capital-funded developments in recent years (Manasseh et al., 2017). Australia's wave energy resource is estimated by Hemer et al. (2017) to be the largest on Earth and although predominantly focused around the southern half of the country, it is estimated that wave energy alone could contribute up to $11 \%$ of Australian's total energy needs by 2050 (Behrens et al., 2012).

Solar energy has the potential to provide the total annual worldwide energy requirement, given the sufficient solar energy that is cast onto the Earth's land area, on average receiving $1.6 \mathrm{MWh} / \mathrm{m}^{2}$ of solar energy annually (Geoscience Australia, 2018e). However, annual solar radiation varies considerably around the world (Bahadori and Nwaoha, 2013) - refer to Fig. 2. The Red Sea area (including Egypt and Saudi Arabia) has the highest amount of solar radiation, while Australia and the United States receive above-average solar radiation.

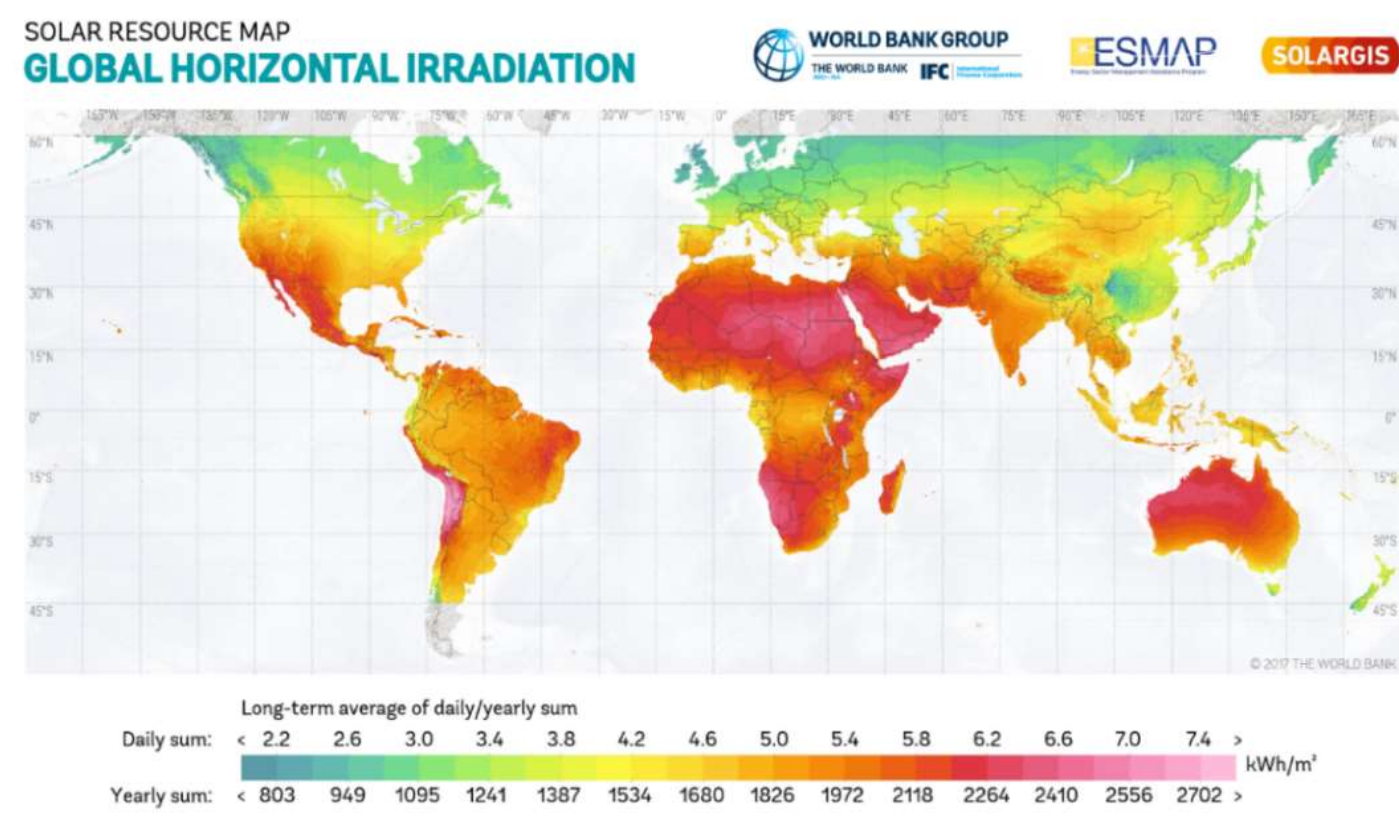

Fig. 2. Global horizontal irradiation. (Source: The World Bank Group (2016)). 


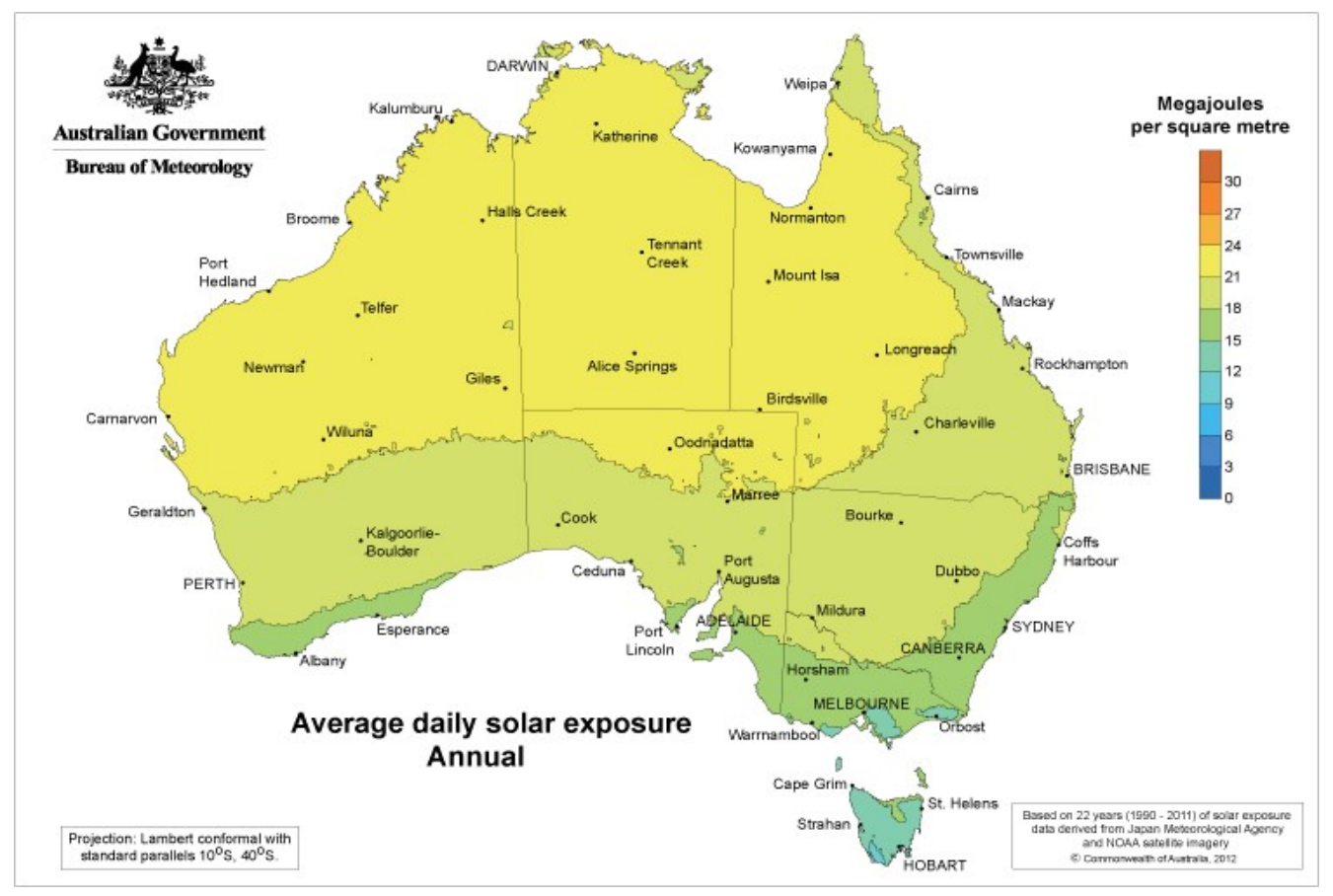

Fig. 3. Australian average daily solar exposure levels. (Source: Bureau of Meteorology (2016)).

As detailed in Fig. 3, the greatest solar resources within Australia are largely located in the Northwest and central regions, with lower solar exposure in the South and the Eastern coast. With approximately 58 million Pega Joules (PJ) of solar radiation being emitted on Australia annually (amongst the world's highest average), solar energy offers a vast potential energy source for the country (Geoscience Australia, 2018e).

Despite the relevance, potential and rapid growth in solar energy capture, wind energy (as an alternative mature technology) is the fastest growing renewable energy source in Australia. Wind resources are ample along Australia's coastal regions and part inland and highland areas (D'Souza and Yiridoe, 2014; Prasad et al., 2017). The Australian Energy Technology Assessment predicts that by 2020 wind will be one of the least costly energy generation technologies in the nation (Clean Energy Council, 2018). Small-scale wind turbines can generate sufficient supply to rural communities away from the grid and large-scale wind farms represent a viable alternative to fossil fuels (Yusaf et al., 2011).

Geothermal energy is another potential energy source for Australia even though it is generally not open to conventional harvesting due to the lack of shallow magma flows. Instead, geothermal 
potential is based upon hot rocks and hot rock hydrothermal systems drawn from depths up to $5 \mathrm{~km}$ below the Earth's surface. Despite this, the identified geothermal resources were estimated to be nearly 2.6 million PJ: equivalent to approximately 2,500,000 times Australia's total annual energy consumption (Romanach et al., 2015). Australia's geothermal sector remains in its infancy, with no discernible growth in energy generation from this source and a noticeable lack of research investigation into its potential (Romanach et al., 2015).

Opportunities for bioenergy in Australia abound, with more than 75 million tonnes (Mt) of biomass residues and waste material available annually derived from forest plantations, agricultural residues, and organic wastes (Geoscience Australia, 2018a). Biomass can produce various forms of bioenergy, including the generation of heat and electricity or liquid fuels (Puri et al., 2012). It is estimated that biofuels could reduce Australia's petrol consumption by as much as $10 \%$ to $140 \%$ of 2006 requirements depending upon the feedstock ( municipal waste is deposited in landfills each year in Australia, making waste a viable source of renewable energy production, as well as deviating waste from landfills (CEFC, 2016). Necessary technologies have remained underdeveloped in Australia, where waste contributes to only $0.9 \%$ of Australia's electricity generation - well below that of countries of the Organisation for Economic Cooperation and Development, with an average of 2.4\% (Bioenergy Australia, 2018; CEFC, 2015). There is however, growing recognition of the tremendous opportunity for converting the inherent energy potential in urban waste streams to generate renewable power for local councils as well as state-level

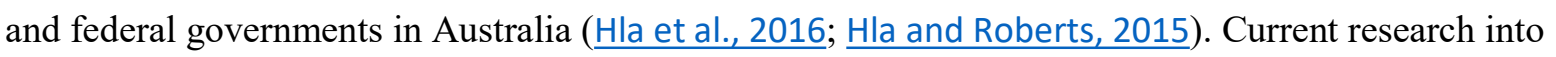
renewable hydrogen extraction from waste biomass provides an exemplar of where further diversification into green fuels are observed. Having commenced in late 2018, this form of hydrogen production (if successful) will eliminate carbon dioxide emissions as a by-product (Geoscience Australia, 2018a).

Australia also has significant opportunities for ocean or marine energy capture and conversion including: mechanical energy from tides, currents and waves; and thermal (otherwise known as ocean thermal) energy from the sun's heat (Behrens et al., 2012; Manasseh et al., 2017). This innate 
renewable energy potential has been recognised by the national government who have funded projects aimed at making this energy form a major contributor to the country's energy mix by 2050 . One of the first outputs of this agenda is the Australian Wave Energy Atlas funded through the Australian Renewable Energy Agency (Geoscience Australia, 2018d; Hemer, M. et al., 2018). As of 2018, this atlas forms part of the Australian Renewable Energy Mapping Infrastructure (AREMI) - refer to Fig. 4 which illustrates major wave energy resources located along Australia's Western and Southern coastlines. The mapping of Australia's tidal energy sources is part of a current project also funded by ARENA; however, existing research suggests that the best tidal energy resources are located along the Northern margin, particularly the North-West coast of Western Australia (Geoscience Australia, $\underline{2018 d) .}$

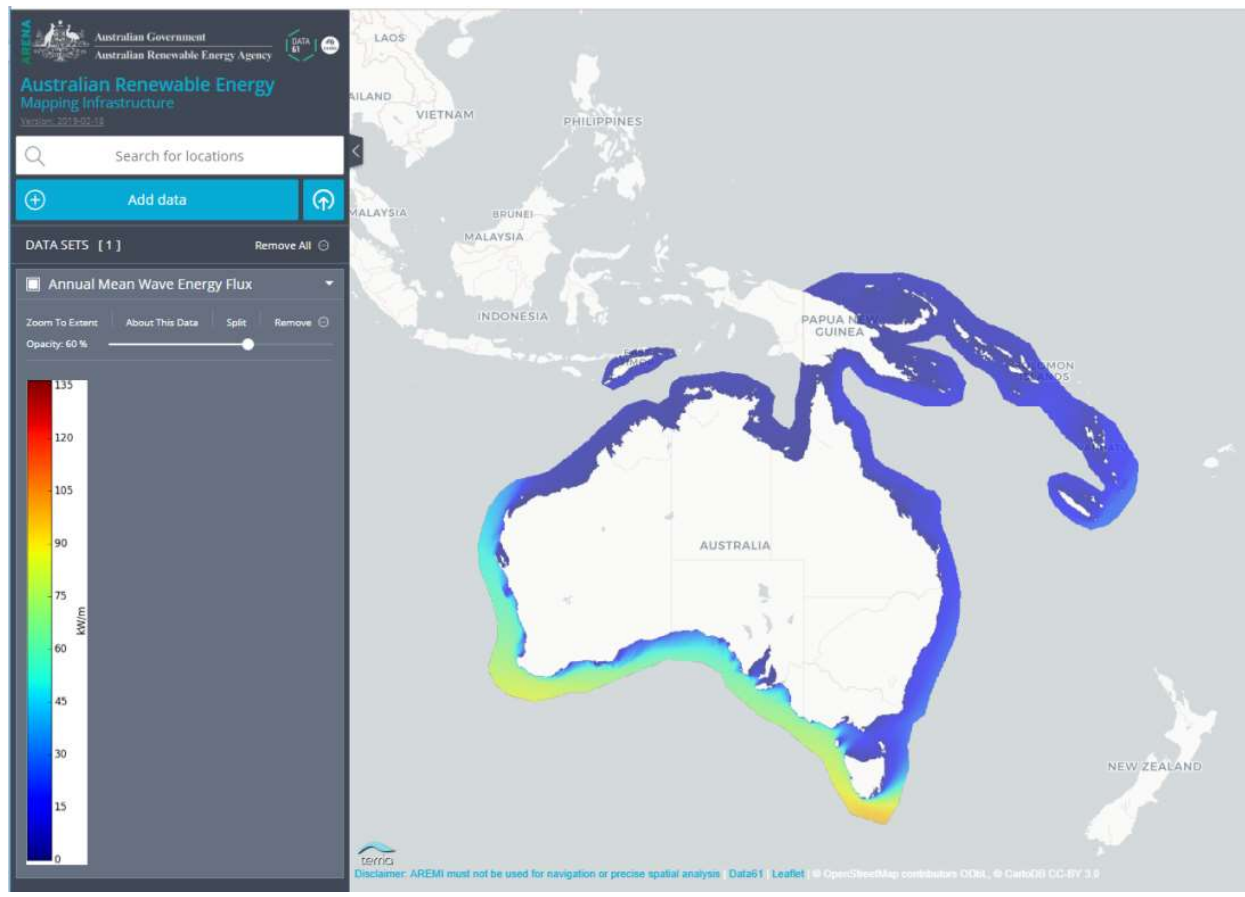

Fig. 4. Australian Wave Energy Atlas. (Source: Hemer, M. et al. (2018)).

Available renewable energy resources can be utilised to generate electricity heat, or transportation fuels to power industry, buildings and transportation (Bahadori et al., 2013a). The International Energy Agency (Brown et al., 2016) maps renewable energy sources against corresponding technology, fuel type and end use (refer to Fig. 5). The energy generated from Australia's renewable 
sources is primarily used within the nation, while energy exported to other countries is generated mainly from fossil fuels.

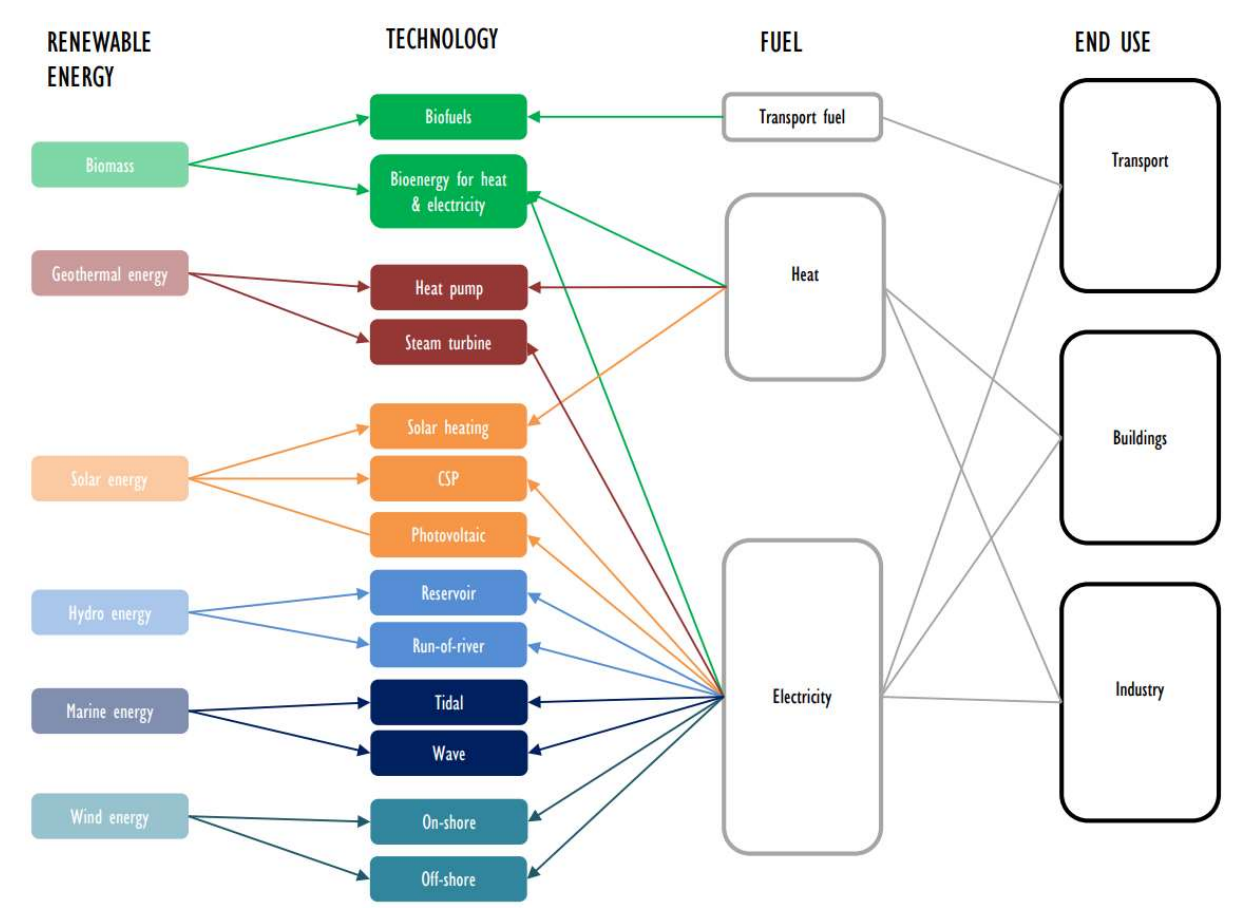

Fig. 5. Renewable energy mapping. (Source: Brown et al. (2016)).

\section{Renewable energy generation in Australia}

Based upon the Australian Energy Update (DEE, 2018) (refer to Figs. 6 and 7), and studies such as Hua et al. (2016), Australia remains heavily reliant upon fossil fuels and is among countries with the highest reliance on fossil fuels for power generation in the world (Baldwin, 2017). Consequently, renewables constitute only $2.1 \%$ of Australia's current total power generation requirements.

Considering electricity generation only, where the use of renewables is generally commonplace, renewables account for only $15.1 \%$ (DEE, 2018). Fig. 6 highlights this clear disproportion and offers a breakdown of renewable electricity generation sources. Fig. 7 expands this information by graphically demonstrating the growth in each of these renewable electricity sources since 1975 - key points identifiable from this chart are:

- Hydropower remains the largest contributor to Australian renewable energy generation, accounting for $40 \%$ in 2016-2017 (see Fig. 7). However, with the rise in wind and solar generation, this is a significant drop from 2001 when it was 95\%. 
- Wind-derived energy has risen steadily over this same period, contributing $31 \%$ of the total renewable energy.

- Solar energy has also increased dramatically in recent years, accounting for $20 \%$ of renewable generation in 2016-2017.

- Bioenergy has however, has remained reasonably static over the last ten years, showing a minor average fall of $0.5 \%$ for the period.

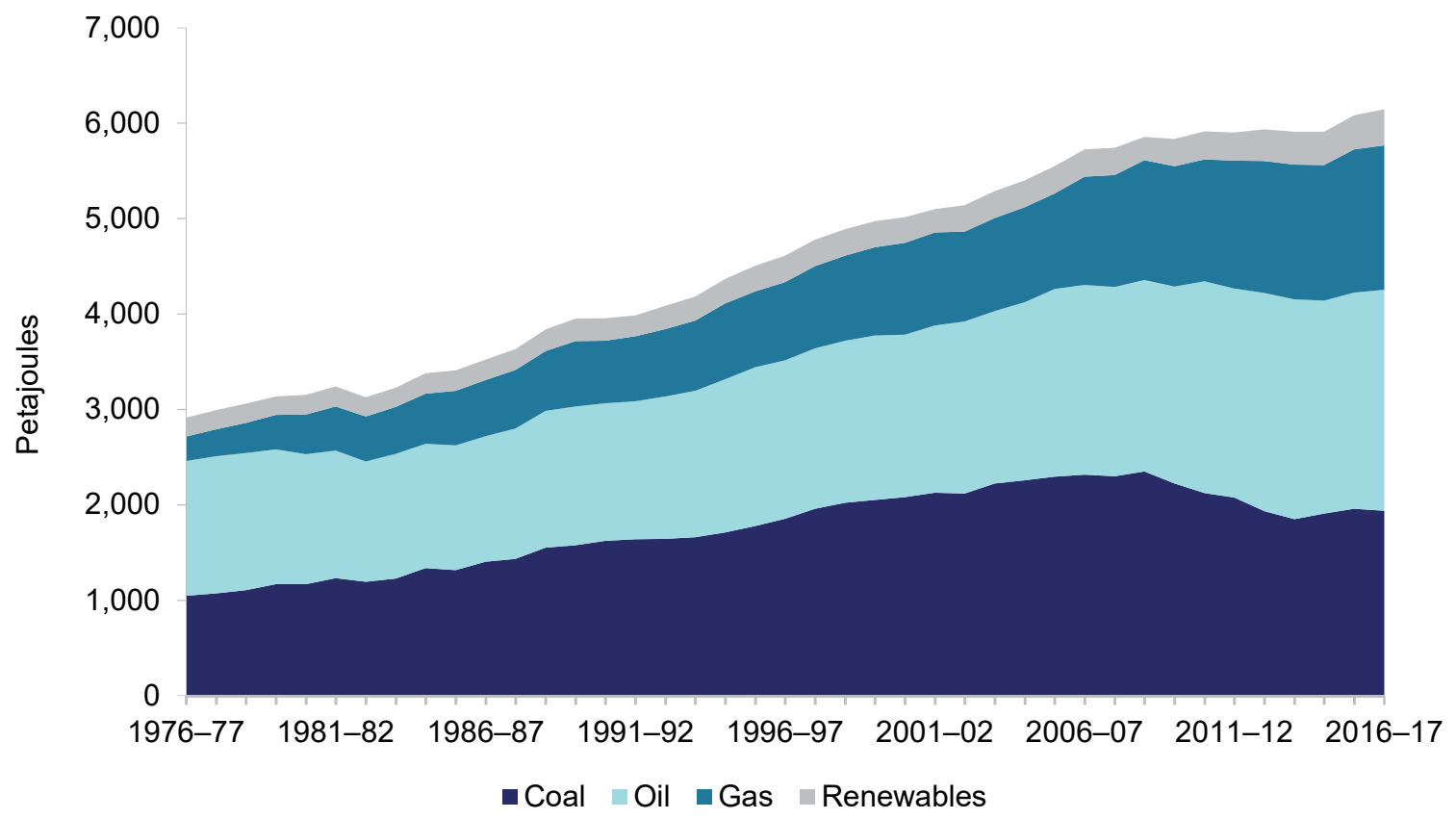

Fig. 6. Australian energy generation by fuel type. (Data Source: DEE (2018)).

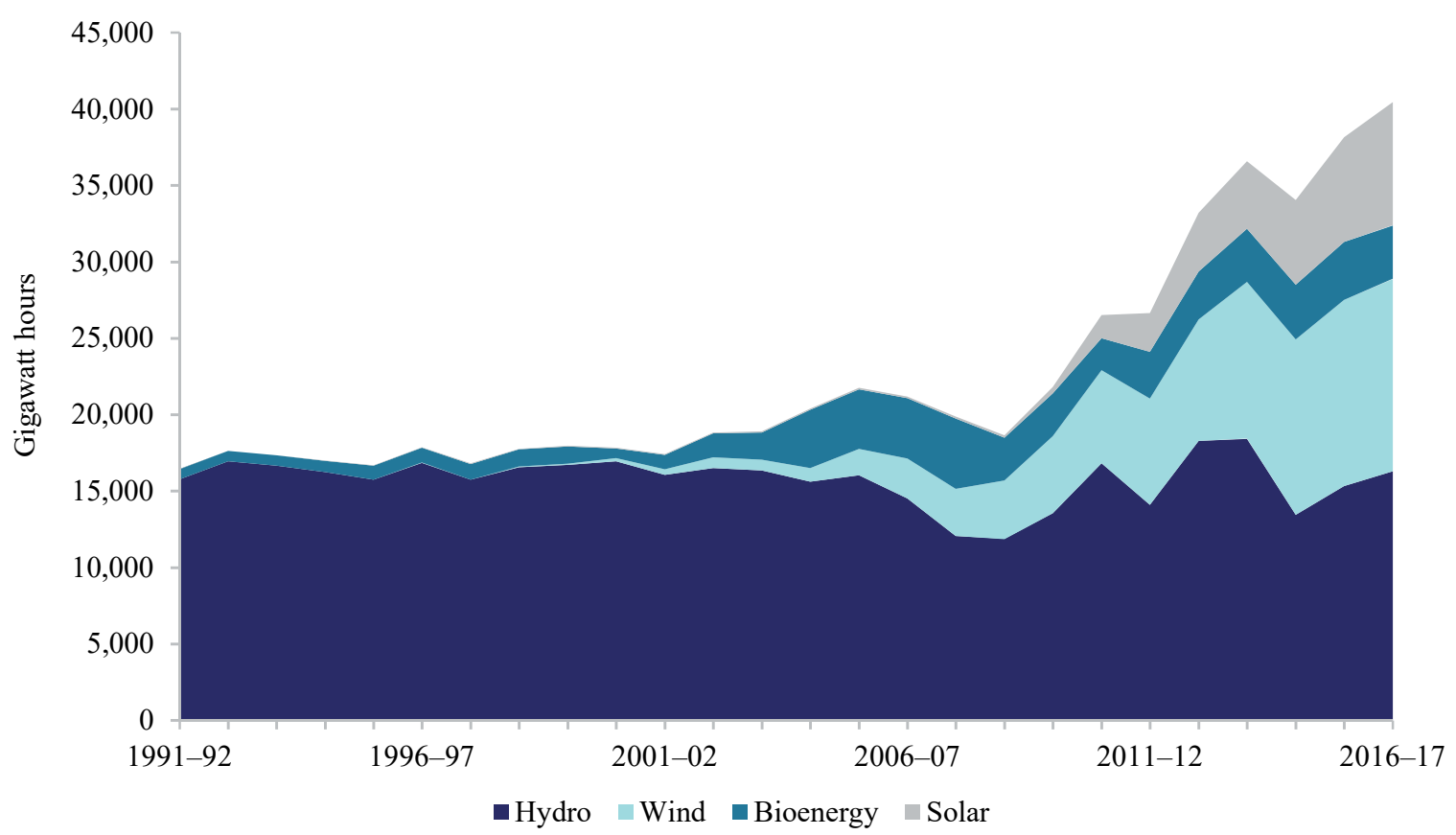


Fig. 7. Australian electricity generation by renewable energy sources. (Data Source: DEE (2018)).

Based on the data provided by DEE (2018) in Table 1, the electricity generated by different sources of renewable energy can be formulised using the deterministic polynomial regression approach. Given the rapid growth in renewable energy in recent years, only data from the last five years is used in the analysis. Regression analysis is a predictive modelling technique used to investigate the relationship between a dependent and independent variable (Harrell, 2015). Linear regression is a basic and commonly used type of predictive analysis typically applied to continuous data (Montgomery et al., 2012). However, it may be difficult to fit data into a line using linear regression line with small error, when the relationship is not naturally linear. In such cases, polynomial regression can be used to fit data into a polynomial equation. Polynomial regression defines a nonlinear relationship between the value of $x$ and the corresponding conditional mean of $y$, denoted $E(y \mid x)$ and can be expressed as (Ekpenyong et al., 2008):

$$
\mathrm{Y}=\theta_{o}+\theta_{1} X+\theta_{2} X^{2}+\ldots+\theta_{m} X^{m}+\text { residual error Equation } 1
$$

where $\theta_{m}$ is the polynomial coefficients, and the goodness of fit can be expressed by the coefficient of determination, $\mathrm{R}^{2}$ which provides a coefficient on the scale of $0-1$; where 1 indicates a perfect fit and 0 indicates no fit

Polynomial linear regression can provide a better approximation of the relationship between dependent and independent variables. A broad range of functions can be defined using this model (Pant, 2019). However, polynomial linear regression can be unsuitable to fit a fourth order polynomial because of the data availability issues. In the case of this study, the installation record data between 2013 and 2017 are only available for large-scale solar PV units. Thus, a third order polynomial model is here adopted for the purpose of predictive analysis. The fitted polynomial regression formulas and the correspongding $\mathrm{R}^{2}$ are displayed in Fig. 8. Model fits are onbserved to provide extremely high for bioenergy $\left(\mathrm{R}^{2}=0.94\right)$, wind $\left(\mathrm{R}^{2}=0.99\right)$ and solar $\left(\mathrm{R}^{2}=1.0\right)$ but also strong for hydro $\left(\left(\mathrm{R}^{2}=0.68\right)\right.$. However, it would be extremely difficult to meaningfully extrapolate these trends into future predictions given the limited time series data avialable. Indeed, and given a longer temproaral series an autoregessive inegrated moving averages (ARIMA) model may provide a better choice of model given that lags in technological or political interventions are likely to impact upon future trends. 
Table 1 - Australian electricity generation by renewable energy sources in the most recent 5 years (Data Source: DEE (2018)).

\begin{tabular}{|l|c|c|c|c|c|}
\hline \multicolumn{1}{|c|}{ Renewable fuels } & $\begin{array}{c}\mathbf{2 0 1 2 - 1 3} \\
\text { (GWh) }\end{array}$ & $\begin{array}{c}\mathbf{2 0 1 3 - 1 4} \\
\text { (GWh) }\end{array}$ & $\begin{array}{c}\mathbf{2 0 1 4 - 1 5} \\
\text { (GWh) }\end{array}$ & $\begin{array}{c}\mathbf{2 0 1 5 - 1 6} \\
\text { (GWh) }\end{array}$ & $\begin{array}{c}\mathbf{2 0 1 6 - 1 7} \\
\text { (GWh) }\end{array}$ \\
\hline Hydro & $16,806.7$ & $14,083.3$ & $14,083.3$ & $18,269.6$ & $18,421.0$ \\
\hline Wind & $6,084.9$ & $6,969.7$ & $6,969.7$ & $7,959.6$ & $10,252.0$ \\
\hline Bioenergy & $2,101.7$ & $3,043.7$ & $3,043.7$ & $3,143.5$ & $3,499.4$ \\
\hline Solar PV & $1,530.4$ & $2,558.7$ & $2,558.7$ & $3,826.3$ & $4,416.0$ \\
\hline 1) Large-scale solar PV & & 49.7 & 107.2 & 457.2 & 672.4 \\
\hline 2) Small-scale solar PV & $3,826.3$ & $4,366.3$ & $5,424.1$ & $6,381.0$ & $7,399.3$ \\
\hline
\end{tabular}

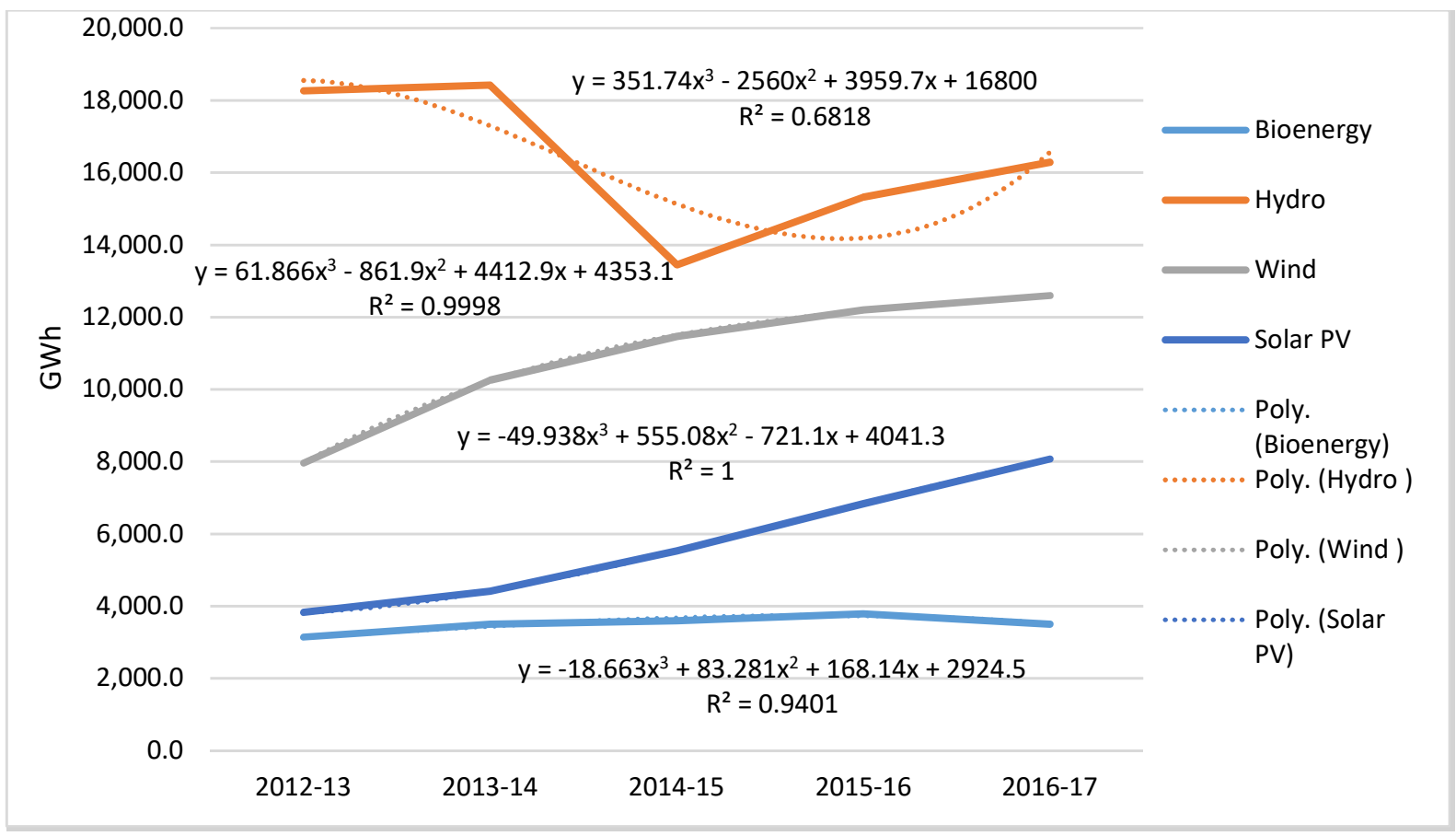

Fig. 8. Australian electricity generation by renewable energy sources and the trend

\subsection{Solar energy}

Solar PVs convert sunlight directly into electricity either via panels installed on buildings and/or infrastructure or alternatively, by large-scale solar power plants (Bahadori and Nwaoha, 2013; Geoscience Australia, 2018e; Rajesh and Carolin Mabel, 2015). Despite Australia's abundant solar energy potential, the comparatively high cost of solar energy technology constitutes a major barrier to large-scale solar energy production (Elliston et al., 2016; Simpson and Clifton, 2016). This position has changed given the advent of major PV and battery storage facilities in Hornsdale and Port 
Augusta in South Australia, and new figures indicate that large-scale solar PV generation will be more cost-effective compared to wind generation by 2020 (Baldwin, 2017). Despite these technological advances, the deployment of large-scale solar PV generation facilities currently remains inchoate in other states. Fig. 9 geographical maps the current distribution of solar power plants with more than 100-kW capacity throughout Australia (Clean Energy Council, 2014), while Fig. 10 displays the electricity generated from solar energy in each Australian state. Combined, these figures indicate that Queensland is the leading solar generator, with the Northern territory generating the least.

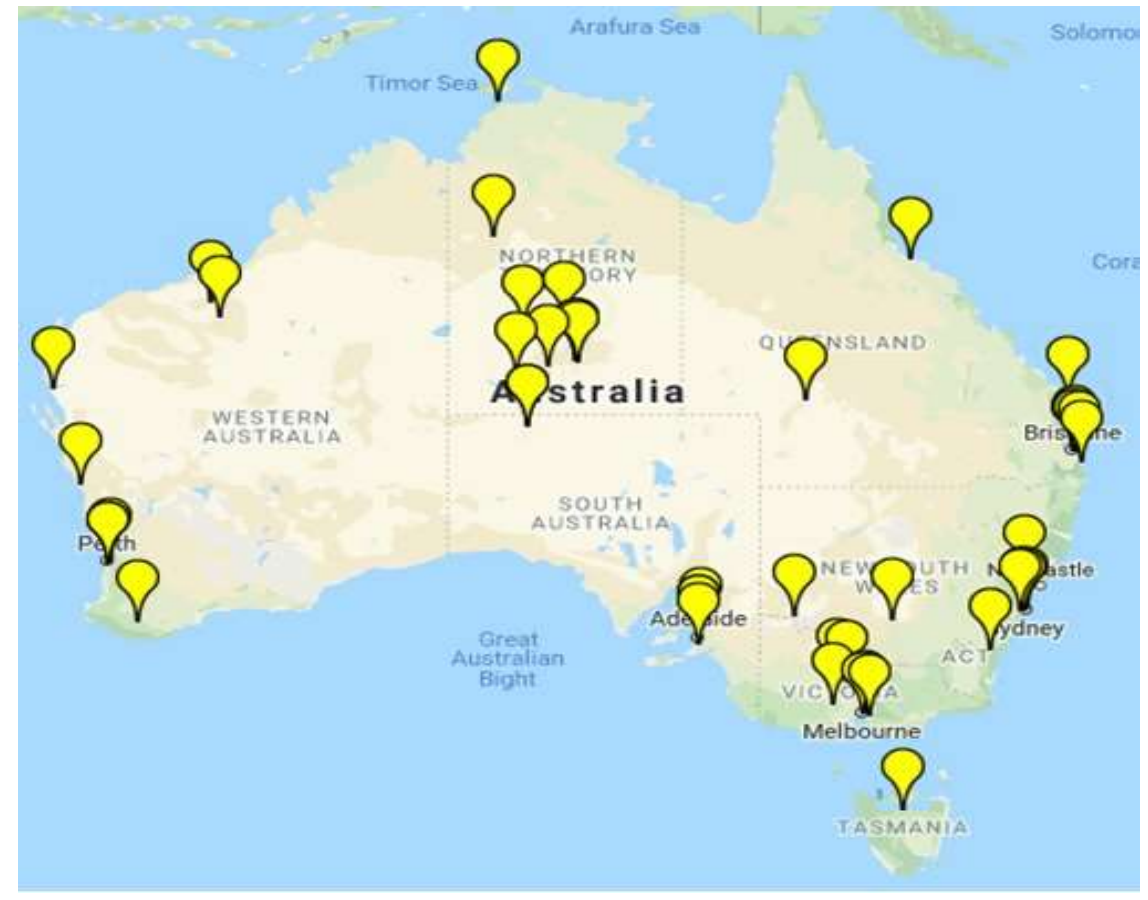

Fig. 9. Solar power plants with a capacity greater than $100 \mathrm{~kW}$. (Source: Clean Energy Council (2014)). 


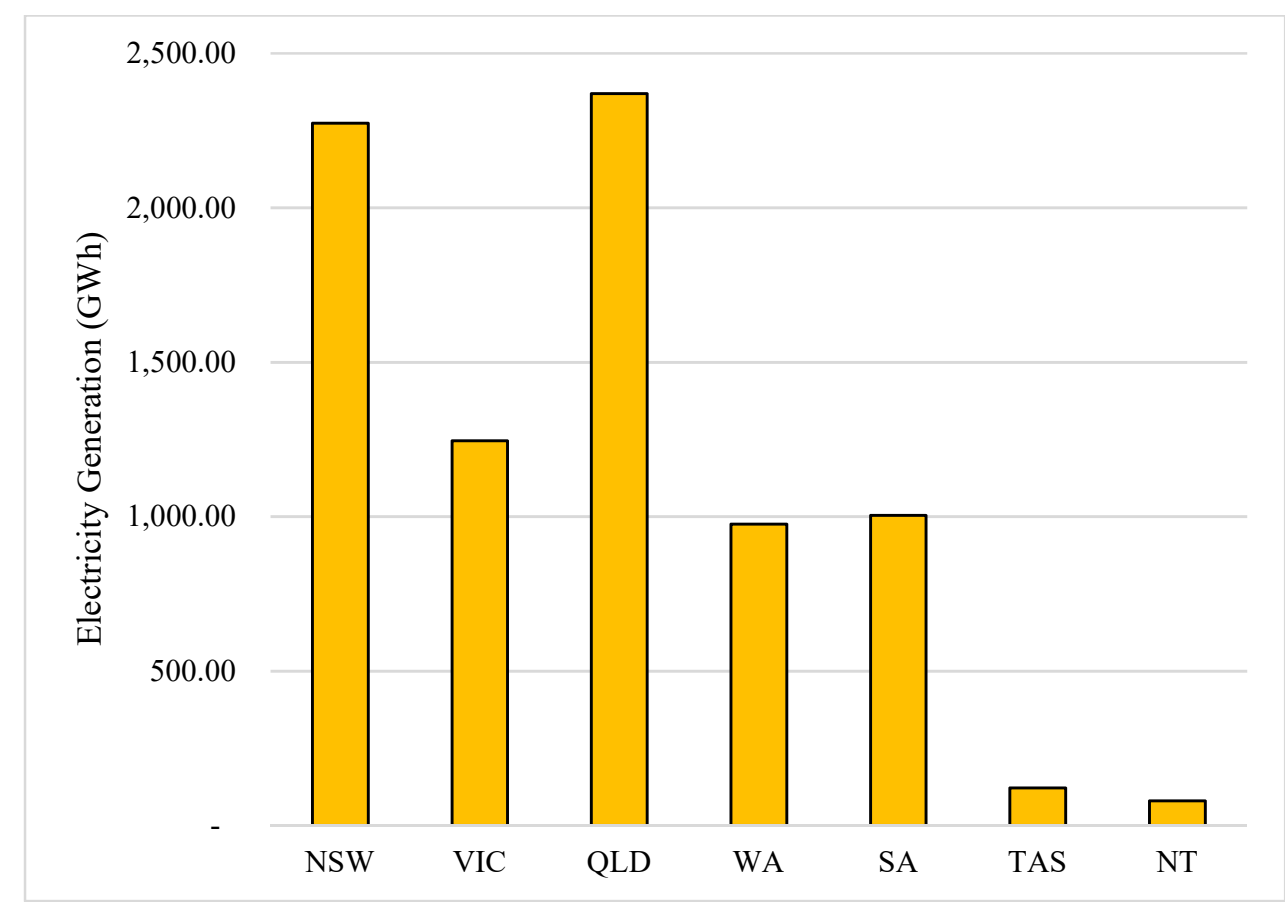

Fig. 10. Electricity generated from solar by state (2016- 2017). (Data Source: DEE (2018)) Notably, small-scale domestic and commercial systems have progressed considerably. Technology advancements in the solar PV industry, concerns about increasing electricity prices and incentives such as FiTs, have significantly enhanced the utilisation of solar to the extent that Australia has exceeded its PV utilisation targets (Chapman et al., 2016; Sommerfeld et al., 2017). Between 2007 and 2011, the cumulative installed capacity of solar PV units increased 100-fold (Nelson et al., 2012; Sommerfeld et al., 2017), giving Australia one of the highest rates of PV use worldwide with approximately two million households having solar rooftops. In addition, the average rooftop PV system capacity increased from $3 \mathrm{~kW}$ to approximately $7 \mathrm{~kW}$ between the years 2012 and 2018 (Baldwin, 2017). In Giga Watt (GW) terms, Australia's PV capacity currently grows at around $1 \mathrm{GW}$ annually - meaning that by the end of 2019 , total installed capacity will reach approximate $9 \mathrm{GW}$ of infeed power to the grid (Geoscience Australia, 2018e). Solar radiation may also be used directly as thermal energy (heat), which is commonly used for hot water systems or the indirect generation of electricity through steam and turbines (Crawford and Treloar, 2004).

\subsection{Wind energy}

Australia's wind resources are mostly found along the Western, Southern, and South-Eastern coastal regions, as well as various parts of its in inland and highland areas. With technological innovations in 
this area entering the market frequently, new regions for wind energy production are being rapidly introduced (Evans et al., 2018; Prasad et al., 2017). Wind energy contributed 33\% to Australia's total renewable energy generation in 2014-2015 (Office of the Chief Economist, 2016), with an increase of 12\% in 2015-2016 (AER, 2017; Hallgren et al., 2014). In South Australia, wind energy supplied 38\% of the state's electricity requirements in 2015-2016 (AER, 2017). Between 2000 and 2015, electricity generation from wind increased from 0.2 TWh to $11.0 \mathrm{TWh}$ and currently, Australia has over 70 wind farms. Fig. 11 illustrates the geographical position of wind power plants with a capacity greater than $100 \mathrm{~kW}$, while Fig. 12 reports upon the electricity generated from wind in each state. South Australia produces one of the highest volumes of wind energy generation in any liberalised energy-only market: wind accounted for $50 \%$ of the total electricity generated over a 9-month period from July 1, 2016, to March 31, 2017 (Geoscience Australia, 2018f). Conversely, the Northern Territory has the least wind energy generation - such is reflective of the states relatively low wind speeds, but high solar radiation. Hence, the Northern Territory government has set a 2030 target to make PV systems its primary renewable energy source.

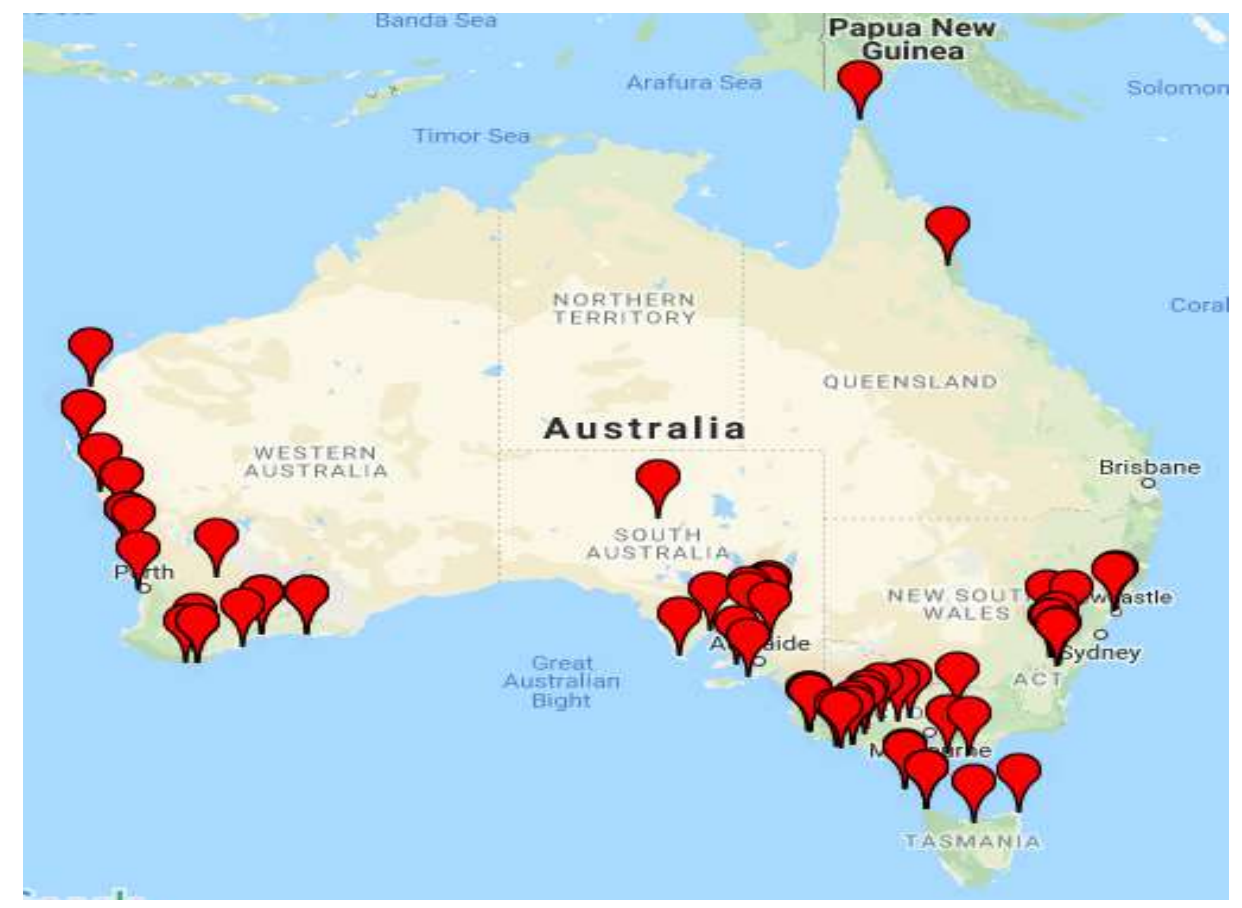

Fig. 11. Wind power plants with a capacity greater than $100 \mathrm{~kW}$. (Source: Clean Energy Council (2014)). 


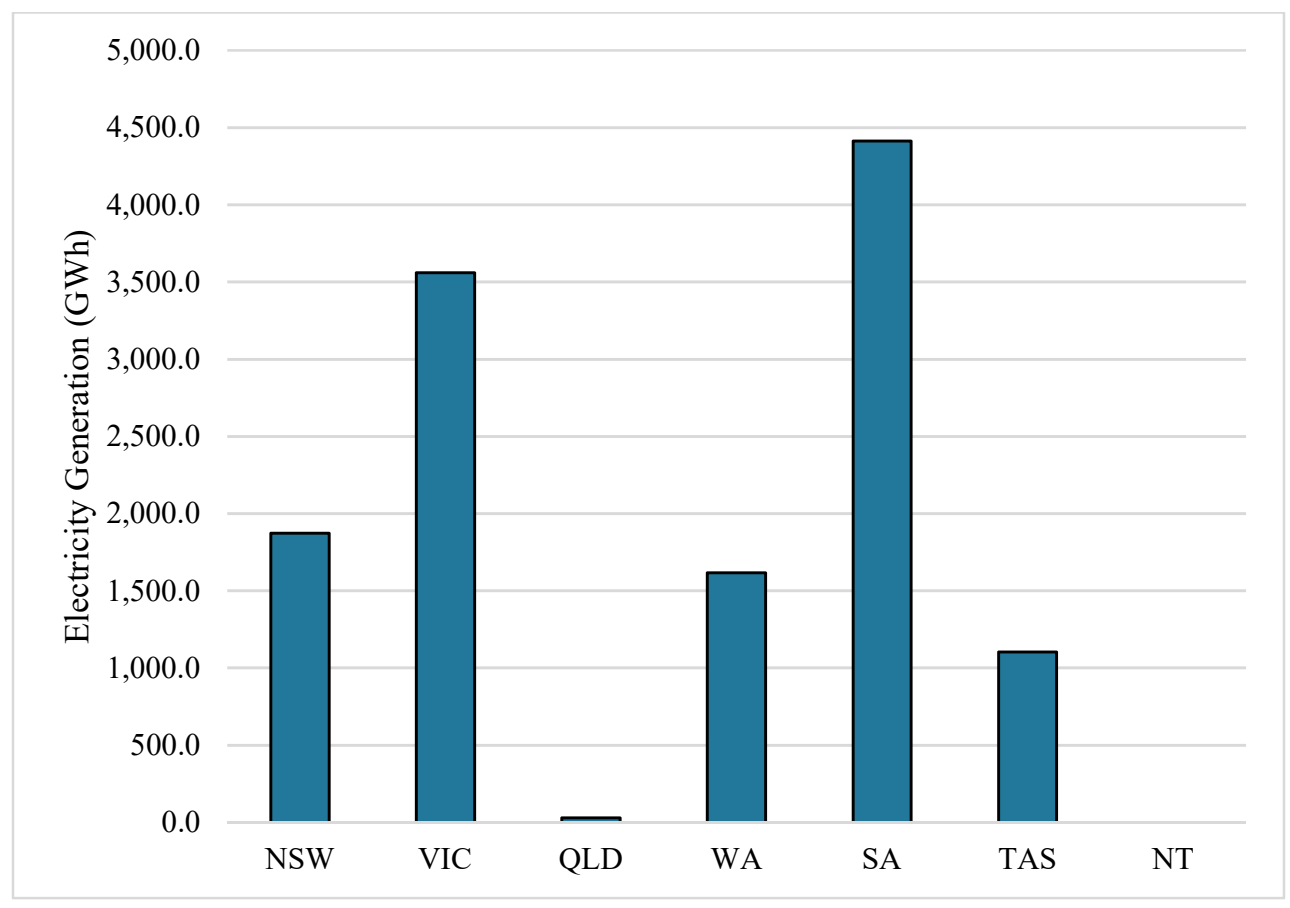

Fig. 12. Electricity generated from wind by state (2016-2017). (Data Source: DEE (2018))

\subsection{Hydropower}

Australia's 124 operating hydroelectric power stations are capable of powering the equivalent of nearly 2.8 million average-sized homes (Bahadori et al., 2013a). The estimated 19,685 GWh of power encompassed 6.5\% of all electricity produced in Australia in 2011 (Bahadori et al., 2013b;

Geoscience Australia, 2018c). Fig. 14 illustrates the geographical position of Australia's hydropower plants with a capacity greater than $100 \mathrm{~kW}$ and Fig. 13 reports upon the electricity generated from hydropower in each state. Tasmania leads hydropower generation, contributing $85.96 \%$ of the electricity generation in 2014-2015 (Australian Department of Industry, Innovation and Science, 2016). New South Wales offers the second most hydropower generation, with an annual generation of over 3,000 GWh. Furthermore, the Northern Territory had no hydropower generation until 2015. These figures reflect the context of those states, being those with large river networks and mountainous regions from which to obtain the requisite elevation to facilitate hydropower generation. 


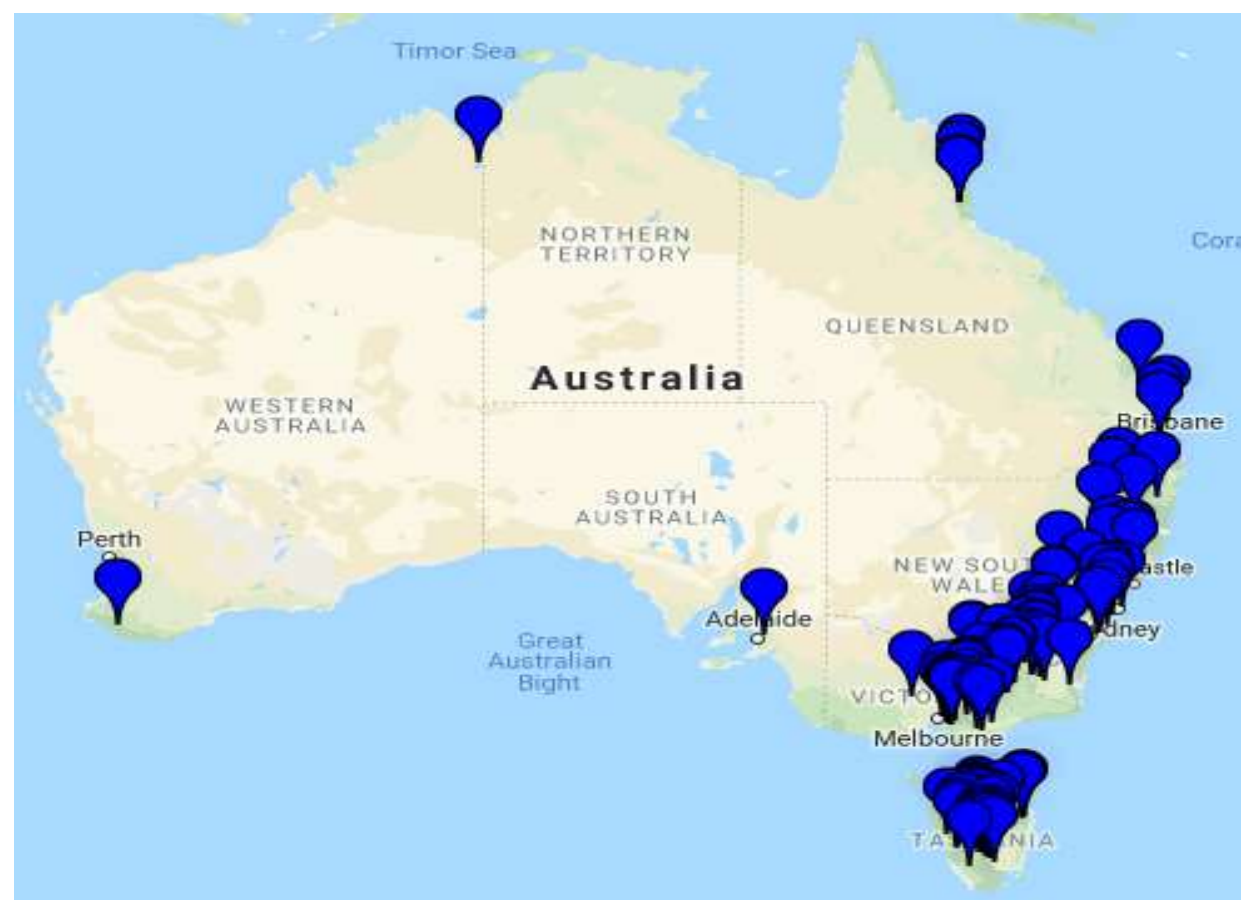

Fig. 13. Hydropower plants with a capacity greater than $100 \mathrm{~kW}$. (Source: Clean Energy Council (2014)).

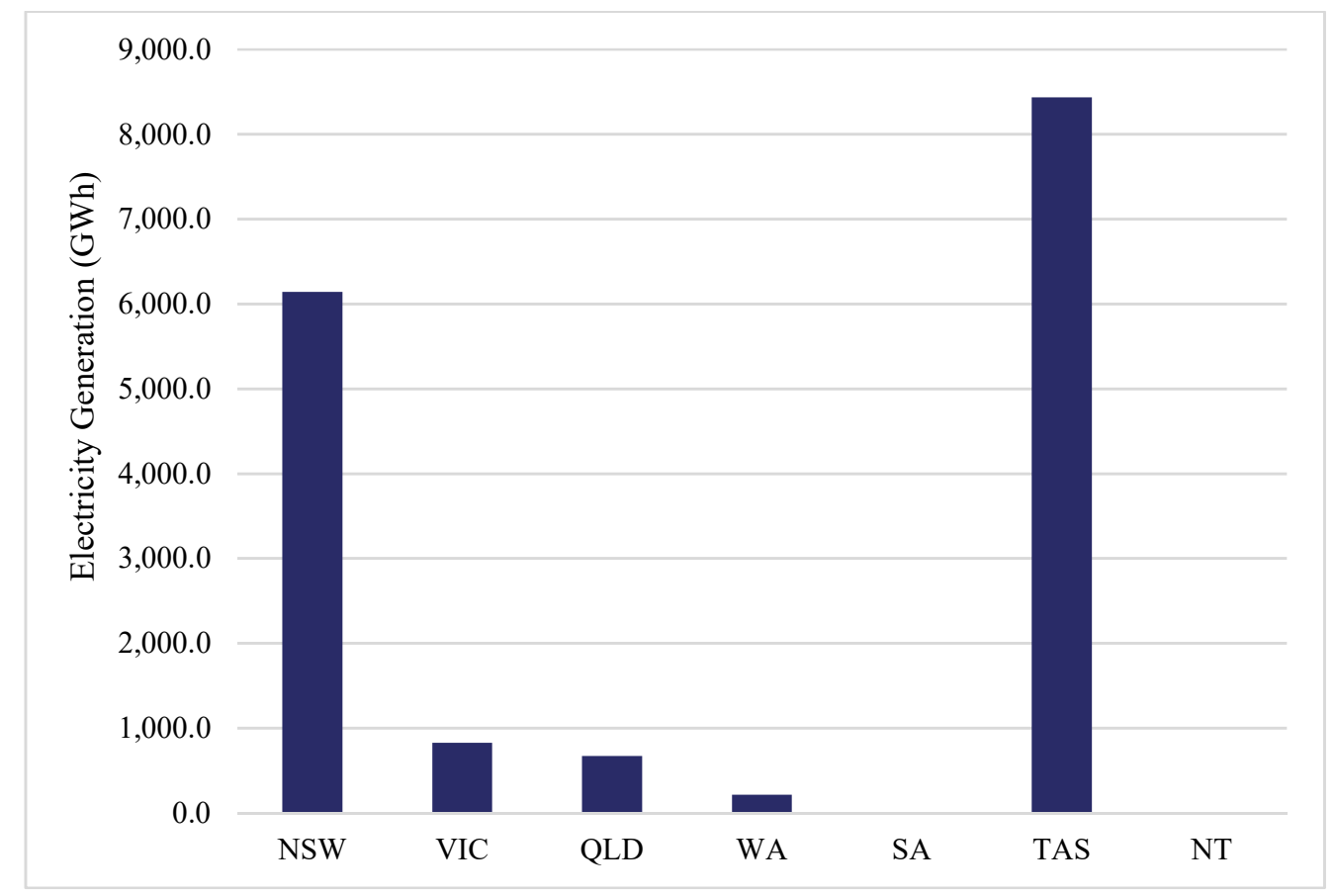

Fig. 14. Electricity generated from hydropower by State (2016-2017). (Data Source: DEE (2018))

\subsection{Other renewable energy sources}


Bioenergy is used to generate electricity, heat and liquid fuels used in vehicles (Geoscience Australia, 2018a; Rahman et al., 2019b). Agricultural, forestry and municipal residue and waste are the common sources of bioenergy fuel, however sugar cane waste (i.e., bagasse) remains Australia's most common fuel source (Bioenergy Australia, 2018; Raison, 2006). Bioenergy accounted for $11 \%$ of the total renewable energy generation in 2014-2015 (Office of the Chief Economist, 2016) with waste alone having the potential to contribute $2 \%$ of the country's electricity requirements (CEFC, 2016). By 2030, this electricity generation from all bioenergy sources may contribute up to $20 \%$ of the country's needs as well as reliably provide approximately $30-40 \%$ of the country's liquid fuel needs by 2020 (Brown and Cowie, 2014).

The identified geothermal energy potential from substantial hot rock geothermal resources (Bahadori et al., 2013c) has attracted multi-billion dollar work commitments in geothermal exploration and development across Australia (Romanach et al., 2015; Siégel et al., 2014). However, to date there are only two pilot power plants with a capacity greater than $100 \mathrm{~kW}$ currently operating in Australia (Clean Energy Council, 2014).

Additionally, marine energy is yet to be significantly tapped in Australia albeit, a number of existing 'government funded' pilot projects have targeted these forms of energy to comprise a valuable part of the overall energy mix by 2050 (Geoscience Australia, 2018d). The first electricity inputs into the grid from tidal-derived energy occurred at Gladstone Port, Queensland, in August 2018. The power was produced through a 2-m marine turbine and the trial in-feed to the grid ran for 3 months. The key industry partner, MAKO Tidal Turbines, expects to expand this successful trial both nationally and internationally for use in remote areas (Gartry, 2018). Wave energy has yet to be harvested at grid infeed levels and is considered to reside in a state of technological infancy.

\section{Policies and Incentives}

Australia's position regarding its Paris Climate Agreement obligations is of considerable concern because it pledged to reduce emissions generated in 2005 by a minimum of $26 \%$ by 2030 (Martek et al., 2019). In addition, independent Australian science advisory groups, such as the Climate Change 
Authority (CCA, 2019), have strongly advocated further reductions to ensure (with 67-75\% confidence) that global warming does not peak beyond $2^{\circ} \mathrm{C}(\mathrm{Ndevr}, 2018)$. Fig. 15 presents an overlay of the current emissions alongside the trajectory required by the Paris agreement and the actual trajectory confronting Australia (Australian Government, 2015; Martek et al., 2018; Ndevr, 2019). In achieving the targeted goals and fulfilling the Paris Climate Agreement obligations, policies and incentives play crucial roles.

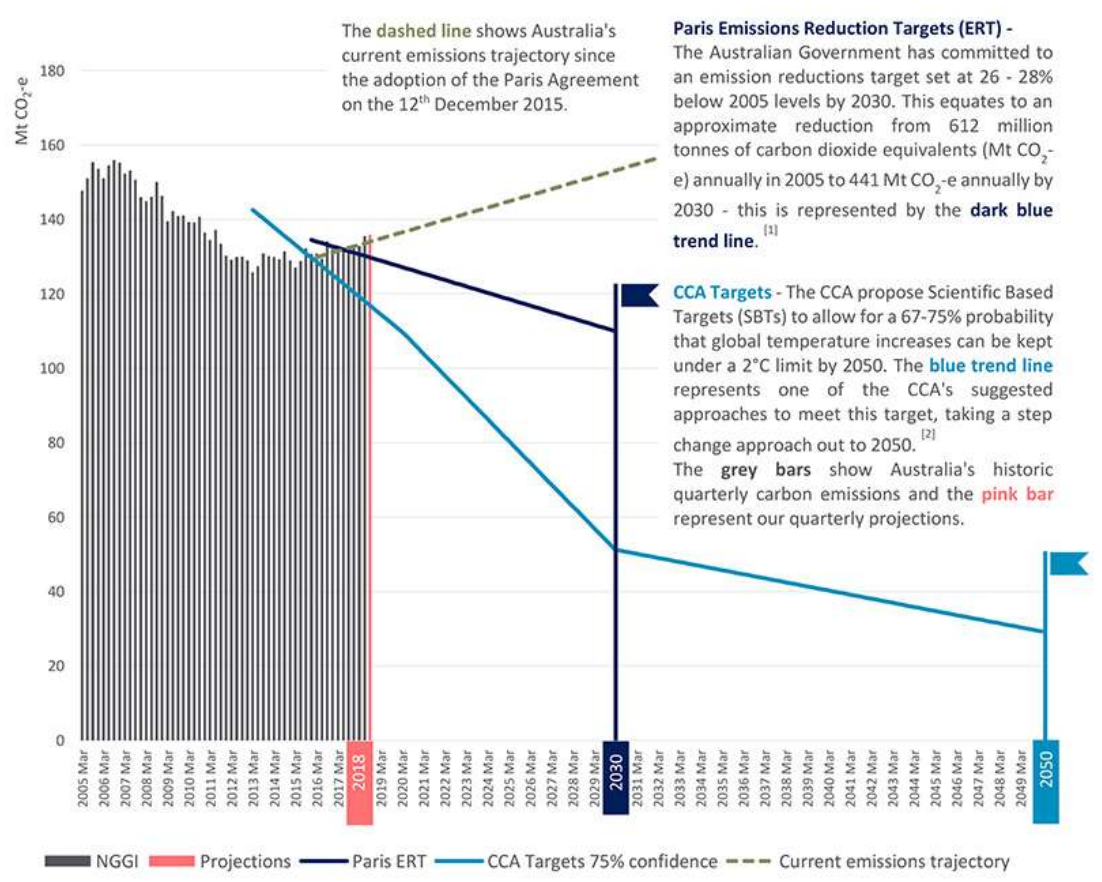

Fig. 15. Tracking Australia's carbon emissions. (Source: Ndevr (2019)).

\subsection{Renewable Energy Targets (RET)}

Government policies, incentives and higher-level support from authorities in Australia are of paramount importance in incentivising the deployment of renewable energy and achieving long-term renewable energy generation targets (Byrnes et al., 2013; Mey et al., 2016). A wide range of renewable energy policies and incentives have been introduced to the Australian market, including: Renewable Energy Targets (RET) nationally and for each state and territory; Feed-in Tariffs (FiTs); Research and Development Programs (RDP); and Emerging Renewables Programs (ERP) (KPMG, 2015), among others. Of these, the national RET and FiTs are the most significant (Byrnes et al., 2013; Lesser and Su, 2008). 
As a Federal Government policy, Australia's RET has been operating since 2001 and is designed to ensure that a minimum of 33,000 GWh of Australia's electricity is derived from renewables by 2020 (Clean Energy Council, 2017; Cludius et al., 2014). The national RET comprises two parts: The Large-scale Renewable Energy Target (LRET) and Small-scale Renewable Energy Scheme (SRES). Under the LRET, entities that make wholesales or nationally wholesale acquisition of electricity directly from a supplier (generally electricity retailers), must obtain and surrender to the government large-scale generation certificates (LGCs) based upon a fixed percentage of their total acquisition. This renewable power percentage (RPP) increases annually until 2020, the 2018 Figure being $16.06 \%$ (Clean Energy Regulator, 2018). The LRET is expected to be met before the 2020 deadline. The SRES effectively subsidises individuals and businesses when installing small systems such as rooftop solar and heat pumps, etc. This incentive occurs through small-scale technology certificates (STCs) granted at the time of purchase based upon a system's generation capacity. Like the LRET, large businesses (and therefore large energy users) must also purchase and surrender a fixed percentage of STCs based upon power consumption. The level of subsidy is reduced each year until the scheme ends in 2030, unless the 2018 review recommendations are adopted, in which case it will end in 2021 as a means of reducing electricity cost (Clean Energy Council, 2018).

Fig. 16 demonstrates the RET progress to 2017, from which it can be observed that approximately $17,500 \mathrm{GWh}$ of renewable energy was generated in 2016 , over halfway towards the target of 33,000 GWh by 2020. RET however, has played a vital role in enabling renewable energy deployment and reducing emissions in Australia in recent years (Cludius et al., 2014) and investigating its impacts has attracted considerable interest from both researchers and policymakers. 


\section{CLEAN ENERGY AUSTRALIA}

\section{PROGRESS TOWARDS THE RENEWABLE ENERGY TARGET}

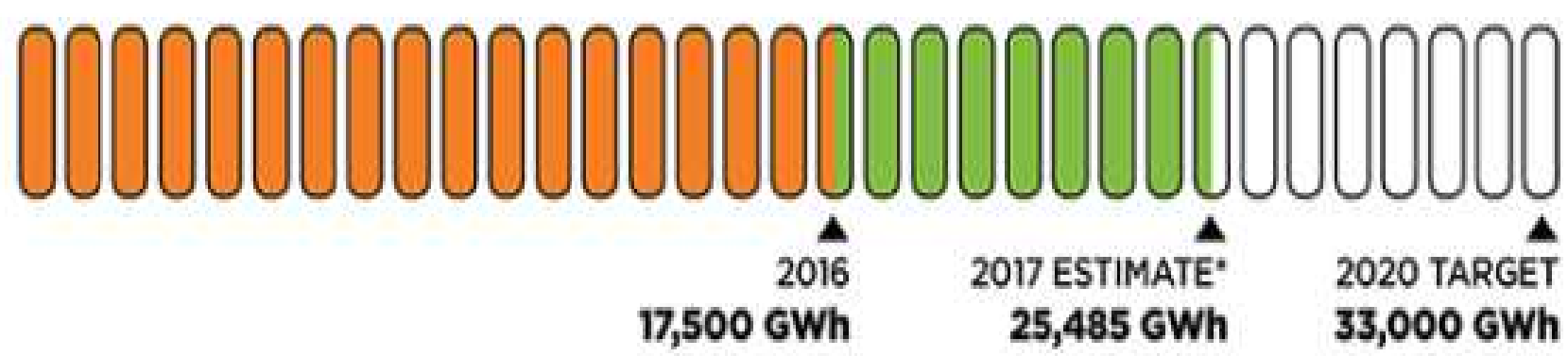

"This figure repreients projects that are underwoy. have been completed or will start in 2017

Fig. 16. RET roadmap. (Source: Clean Energy Council (2017)).

The RET is also supported by the $\$ 10$ billion Clean Energy Finance Corporation (CEFC), which is a government-funded financier formed to invest in renewable energy, low emission technology and energy efficiency in Australia (Lowe, 2012). Circa 50\% of projects under construction or those that began in 2017 and are supported by the RET are large-scale solar due to a plunge in installation cost in recent years, and augmented by technology and financial support from the ARENA and CEFC (Clean Energy Council, 2017).

\subsection{Feed-in Tariffs (FiTs)}

In conjunction with the SRES, most Australian states and territories have implemented various feed-in tariff (FiTs) arrangements to promote the uptake of renewable electricity, primarily in the form of rooftop solar PV systems (Poruschi et al., 2018). Chapman et al. (2016) reviewed the solar PV policies in Australia between 2001 and 2012 (particularly the RET and FiTs) and found that the influence of FiTs on PV installation rates exceeded that of renewable energy certificates (RECs). Furthermore, Poruschi et al. (2018) reviewed FiTs for residential small-scale PV installations across Australia, finding that policies on FiTs correspond to a greater number of electricity disconnections from the grid. Their research ( $i b i d$ ) has laid a foundation for future Australia-wide policy analysis. 
Chapman et al. (2016) reviewed the historical rates of FiTs until 2012 for each state across Australia (refer to Table 1) and similarly, Energy Matters (2018) also summarised the current rate of FiTs for each state (refer to Table 2). The variations of the FiT rates, from year-to-year and from state-to-state, can be observed in both Tables 2 and 3. For example, the rate of FiTs in Victoria, which held at 60ф/kWh from 2009 to 2011, dropped to $9.9 \notin / \mathrm{kWh}$ in 2018.

Table 2 - FiTs in Australia, 2008-2012 (Source: Chapman et al. (2016)).

\begin{tabular}{|c|c|c|c|c|c|}
\hline State & 2008 & 2009 & 2010 & 2011 & 2012 \\
\hline SA & $44 C$ & $44 c$ & $44 c$ & $44 c \circ 16 c(10 c t)$ & $16 c$ \\
\hline WA & No FiT & NoFiT & $40 \mathrm{c}$ & $40 c \Rightarrow 20 c(1 \mathrm{Jul}) \Rightarrow$ Closed (1 Aug $)$ & No Fit \\
\hline TAS & 1 for 1 & 1 for 1 & 1 for 1 & 1 for 1 & 1 for 1 \\
\hline VIC & No Fit & $60 \mathrm{c}$ & $60 c$ & $60 c$ & $25 \mathrm{c}$ \\
\hline NSW & No Fit & No Fit & $60 \mathrm{c}$ Gross $\Rightarrow 20 \mathrm{c} \mathrm{Net}(270 \mathrm{ct})$ & $20 \mathrm{c} \backsim$ Closed (28 April) & No Fit \\
\hline $\mathrm{ACT}$ & No Fit & $50.5 \mathrm{c}$ & $50.5 \mathrm{c}$ Gross $\rightleftharpoons 45.7 \mathrm{c}(1 \mathrm{Jul})$ & $45.7 \mathrm{c} \in$ Closed ( 30 May) & No Fit \\
\hline QLD & $44 C$ & $44 c$ & $44 \mathrm{c}$ & $44 \mathrm{C}$ & $44 c \Leftrightarrow 8 c(10 \mathrm{Jul})$ \\
\hline
\end{tabular}

Notes: $₫$ shows a change in tariff, 1 for 1 means that the tariff is equal to the price of electricity.

Table 3 - Current Rate of FiTs (Source: Energy Matters (2018)).

\begin{tabular}{l|l}
\hline State & Current Rate of FiTs \\
\hline Australian Capital Territory & $6 \notin$ to $12 \phi / \mathrm{kWh}($ depending on retailer) \\
New South Wales & $11.9 \phi$ to $15.0 \phi / \mathrm{kWh}$ (depending on retailer) \\
Queensland & $6 \notin$ to $12 \phi / \mathrm{kWh}$ (depending on retailer) \\
South Australia & $11 \phi$ to $16.3 \phi / \mathrm{kWh}$ (depending on retailer) \\
Tasmania & $8.9 \phi / \mathrm{kWh}$ \\
Victoria & 9.9 to $29 \mathrm{c} / \mathrm{kWh}$ (depending on retailer) \\
Western Australia & $7.1 \phi / \mathrm{kWh}$ under the State Government's Renewable Energy \\
& Buyback Scheme \\
\hline
\end{tabular}

The payback period is an important incentive parameter associated with FiTs and the installation of PV installations. This is characterised as the year when the cumulative cost of a solar PV system is offset by the total cumulative savings (Stoppato, 2008); where savings represent the avoided cost of consumption plus any revenue received from FiTs and the cumulative cost represents the initial investment and the time value of money (Australian Energy Council, 2018). The payback period of a solar PV system depends on various factors, including FiTs, other incentives offered by government such as SRES, electricity generation and usage, electricity cost etc. The payback period is a 
determining parameter for the renewable energy decisions made by policy officers and the owners of households and businesses (Stoppato, 2008). The Australian Energy Council (2018) proposed a methodology to calculate the payback period, considering initial investment, discount rate, efficiency, system degradation rate, export rate, avoided usage cost and the rate of FiTs. Based on this methodology, the payback period of solar PV systems was calculated for each capital city in Australia, and the payback period with discount rates of $6.64 \%$ is illustrated in Fig. 17 as an example. From this example, it can be observed that overall the payback ranges from approximately 3 years to over 30 years. The payback period is therefore inconsistent in various regions/cities and may be too long in some areas.

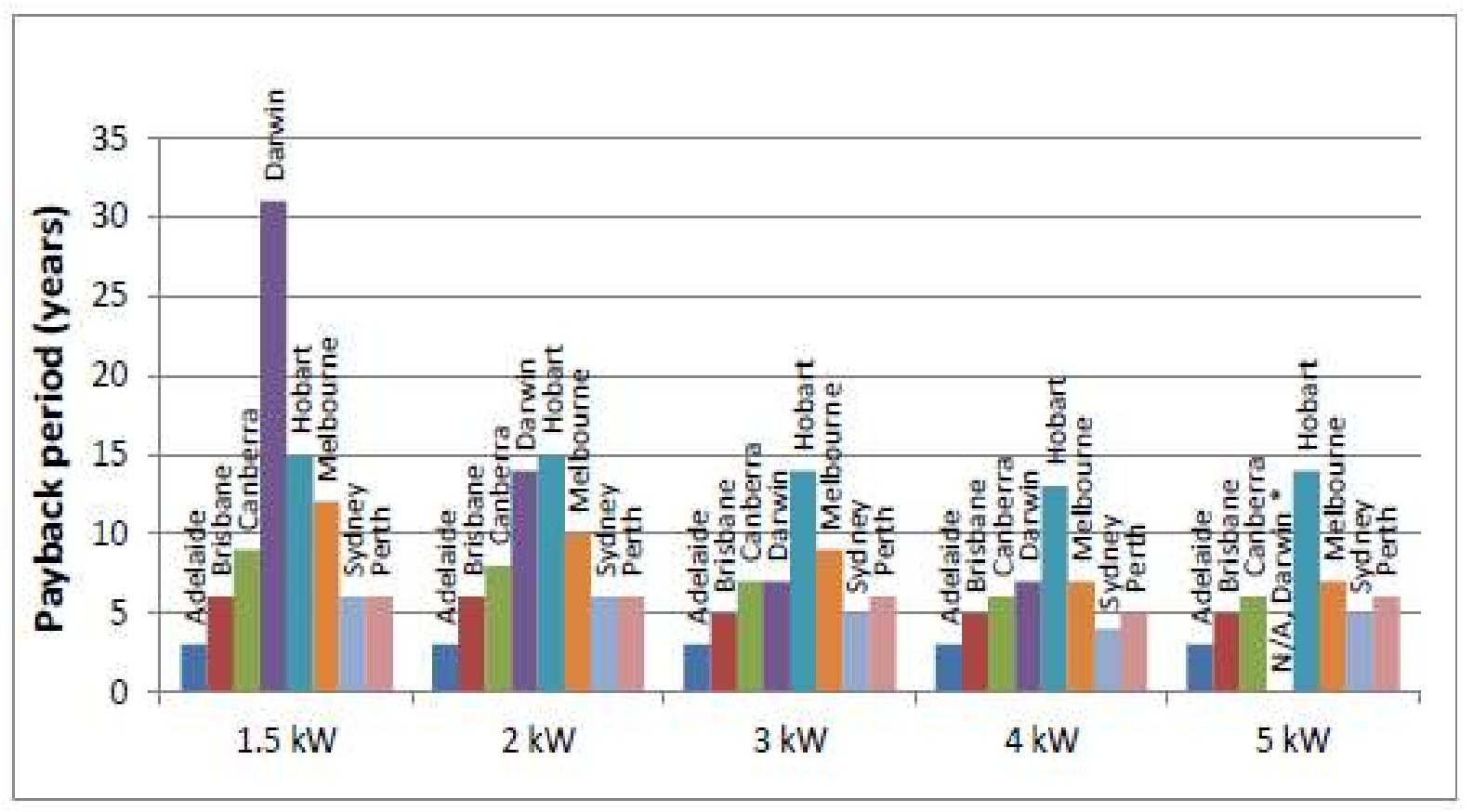

Fig. 17. Payback period of solar PV system with a discount rate of $6.64 \%$. (Source: Australian Energy Council (2018)).

\subsection{Time-Varying FiTs (TV FiTs)}

Currently, FiTs, or FiT-like systems are utilised in more than 75 countries to ensure that investors or homeowners receive known payments for the electricity they feed into the grid. A FiT system however, does not provide any incentive to reduce power consumption in peak periods, or otherwise use electricity wisely. With the advent of smart metering technology, coupled with energy shortages, 
both suppliers and consumers are seeking to develop improved pricing mechanisms to enhance efficiency and reduce cost. The time-varying FiTs (TV FiTs) is one such solution.

Under TV FiTs, electricity is priced higher during peak periods than during non-peak periods. TV FiTs aim to reduce peak period loads and thus promote the security of electricity supply. With TV FiTs, homeowners and companies with solar PV systems are encouraged to export more power into the grid when demand for electricity is higher (Government of Victorian, 2018). Consumers are also incentivised to change their electricity-use behaviour, shifting some of their electricity use from peak to off-peak hours, thereby reducing electricity loads during peak periods. The states of Victoria, New South Wales and Queensland all have implemented TV Fits.

\section{(1) Victoria}

In the state of Victoria, electricity is competitively marketed to consumers through multiple retailers. In July 2018, Victoria introduced a TV FiT and the retailers are now positioned to offer this as a 3-tier system of tariff option for customers (refer to Table 4 and Fig. 18). This new TV FiT offers a lower rate $(7.1 \mathrm{c} / \mathrm{kWh})$ during off-peak times, a marginally higher rate $(10.3 \mathrm{c} / \mathrm{kWh})$ during shoulder hours and a significantly higher rate $(29 \mathrm{c} / \mathrm{kWh})$ during peak hours.

Table 4 - Victorian 3-tier Time-Variable FiTs system.

\begin{tabular}{llll}
\hline Period & Weekday & Weekend & Rates \\
\hline Off-peak & $10 \mathrm{pm}-7 \mathrm{am}$ & $10 \mathrm{pm}-7 \mathrm{am}$ & $7.1 \mathrm{c} / \mathrm{kWh}$ \\
Shoulder & $7 \mathrm{am}-3 \mathrm{pm}, 9 \mathrm{pm}-10 \mathrm{pm}$ & $7 \mathrm{am}-10 \mathrm{pm}$ & $10.3 \mathrm{c} / \mathrm{kWh}$ \\
Peak & $3 \mathrm{pm}-9 \mathrm{pm}$ & $\mathrm{n} / \mathrm{a}$ & $29 \mathrm{c} / \mathrm{kWh}$ \\
\hline
\end{tabular}




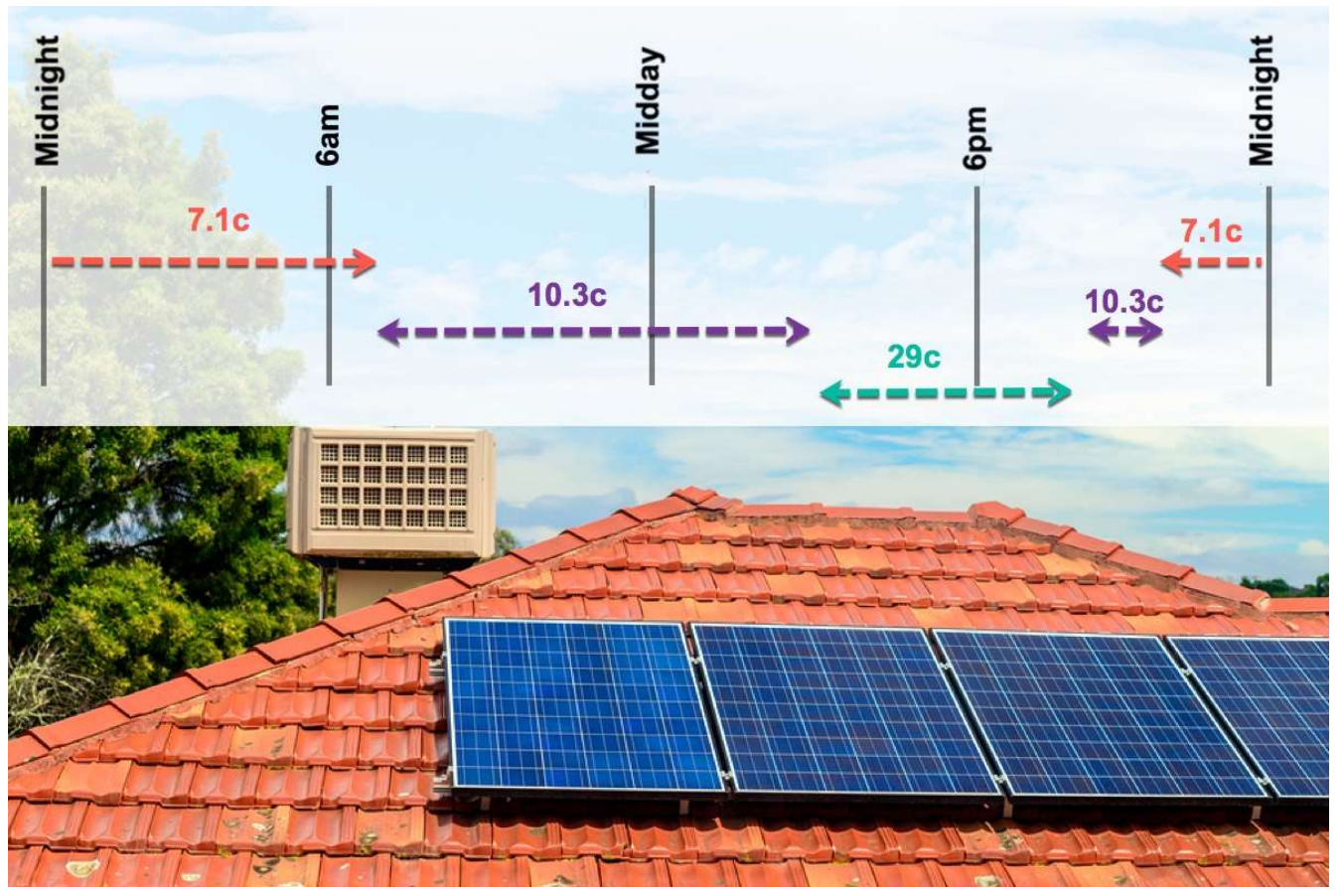

Fig. 18. TV FiTs in Victoria. (Source: Brakels (2018)).

Similar to a single FiT system, the TV tariffs comprise of a the projected wholesale spot price adjusted by losses, market fees, ancillary service charges and the avoided cost of carbon. Unlike the single FiT however, TV FiTs are weighted to account for the blocks of time to which the electricity is exported.

Along with the customers' willingness to participate in the TV FiTs, the influence of the Victorian TV FiT on the electricity supply and the customers' benefits is yet to be studied given insufficient data available.

\section{(2) New South Wales}

In New South Wales, retailers can choose whether or not to offer FiTs to their customers, and decide the level of the FiTs that they offer. However, to help guide retailers and customers, New South Wales's regulator IPART recommends a benchmark for solar-feed in tariffs each year. The benchmark range for the fixed FiT for 2018-19 is 6.9 to $8.4 \mathrm{c} / \mathrm{kWh}$. Moreover, following Victoria, the IPART has also set TV FiTs taking into account the different values of solar exports at different times of the day (Solar Choice, 2018).

\section{(3) Queensland}

The major feature that differentiates Queensland from other states is that there are two types of 
pricing systems between South-East Queensland (i.e. the most urbanized area including the state capital, Brisbane) and the regional areas of Queensland (Poruschi et al., 2018). The TV FiTs are only available for the regional areas. Under the time-varying scheme, customers will be paid $13.730 \mathrm{c} / \mathrm{kWh}$ within the peak period (3pm-7pm) and $5.796 \mathrm{c} / \mathrm{kWh}$ (all other times) (Queensland Government, 2018). However, as shown in Fig. 19, the QCA's impact analysis suggested that typical solar PV customers in regional Queensland are unlikely to benefit from accessing a time-varying solar price, compared with the flat feed-in tariff for 2018-19 of $9.369 \mathrm{c} / \mathrm{kWh}$ (Queensland Competition Authority, 2018).

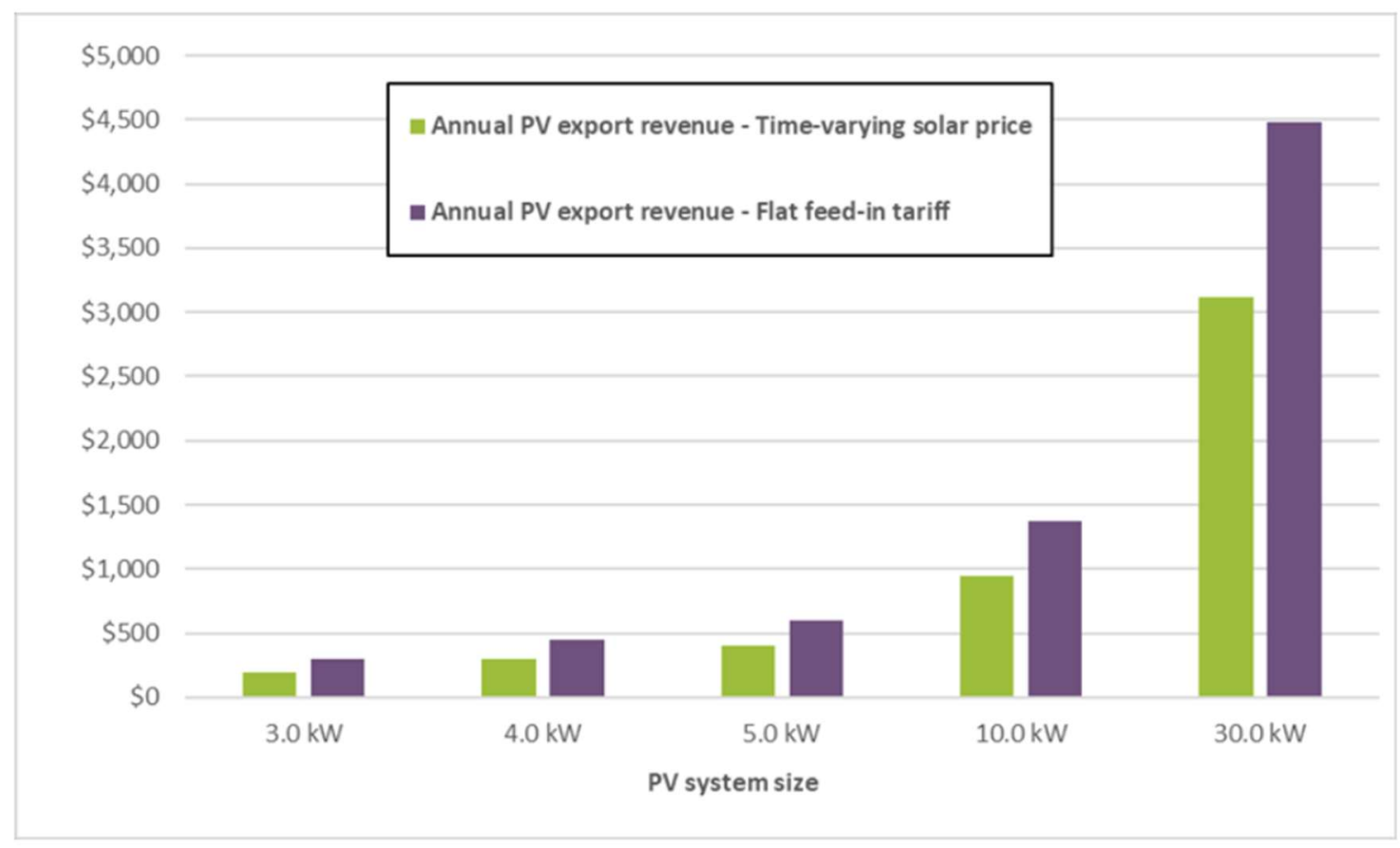

Fig. 19. Indicative Financial Outcomes of Net PV Export, 2018-19. (Source: Queensland Competition Authority (2018))

\section{Discussion}

Although Australia has abundant renewable energy resources, the country remains heavily reliant upon fossil fuels. Only $6 \%$ of Australia's total energy consumption was derived from renewables, and $82.7 \%$ of electricity was generated from fossil fuels in 2016. In fact, the utilisation of renewable energy remains far from satisfactory (Hemer, M.A. et al., 2018). The recent closure of several coalfired power stations has resulted in withdrawing over 2,000 MW from the market and with energy 
demand continuing to increase, Australia must establish an alternative energy supply mode and transform energy supply to a cleaner and more sustainable pathway. Accumulation of these facts augmented with other findings of the present study are encapsulated into a conceptual framework roadmap (refer to Fig. 20), a description of which follows.

The way forward

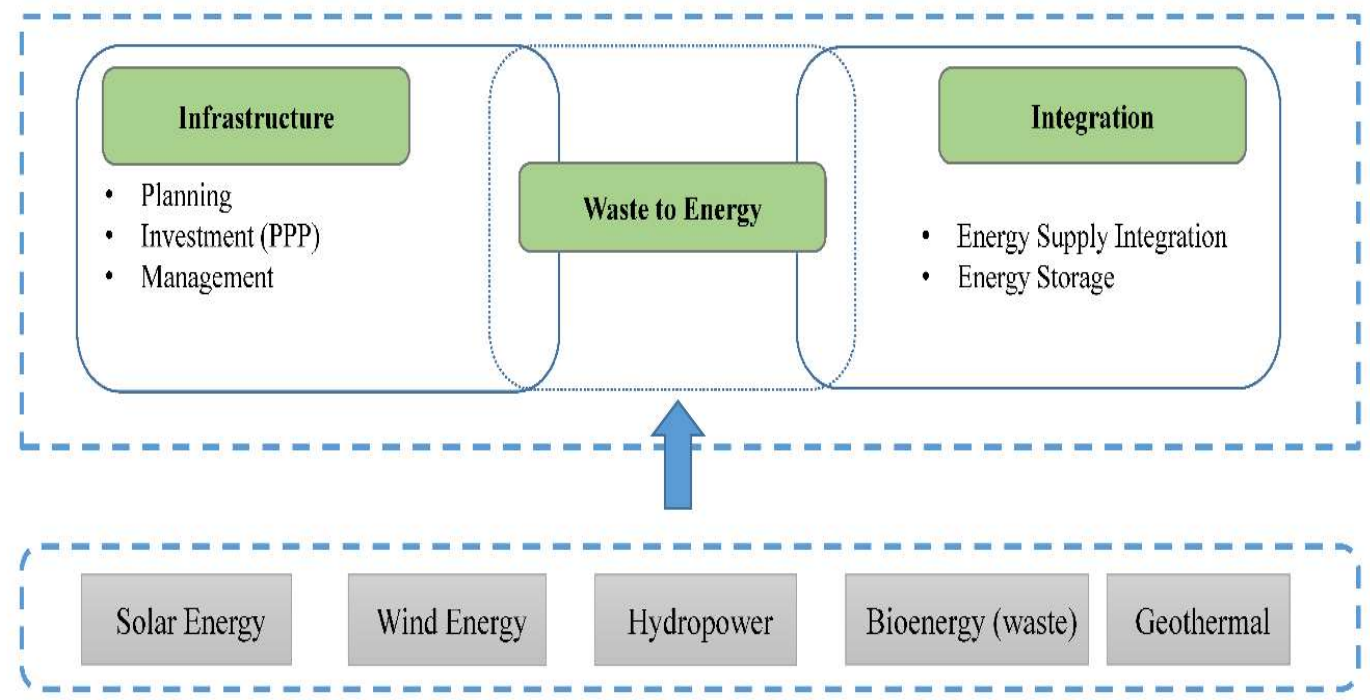

Potential

Fig. 20. Proposed roadmap towards renewable energy enhancement in Australia.

I. Australia's potential renewable resources (solar, wind, wave, geothermal and biomass) are diverse and widely distributed across the country. However, most of these have fluctuations in supply, resulting in risks and uncertainties in serving the regional energy markets. As illustrated in Fig. 19, future attempts must consider technological developments in integration with the various sources of renewable energy, where fluctuations of one source in a region can be compensated with in-feed from another source. The roadmap therefore, prescribes more research activity, incentives and funding that is needed to ensure the integration of various renewable energy sources (Hoicka and Rowlands, 2011), utilisation of hybrid arrangements (Olatomiwa et al., 2016), and development of storage systems and facilities (Vieira et al., 2017). With the recent social acceptance and interest in adopting waste-toenergy techniques across the country (CEFC, 2016), waste can be seen as a central element of such hybrid systems in all regions across Australia. Given the scarcity of research on the 
potential of integrating waste with other sources of energy in Australia, further research on the topic is suggested. Furthermore, the utilisation of geothermal energy is forecast to expand rapidly in the following years with significant financial support available (ARENA, 2019).

II. Infrastructure, technology and corresponding research into the potentials for utilising available sources of renewable energy have remained underdeveloped and insufficient (Yusaf et al., 2011), particularly for readily available sources like waste (Hla et al., 2016). Given the amount of investment necessary, policy incentives on infrastructure development and technology innovation are needed. The lessons learned from other countries, such as China, in drawing upon Public Private Partnership (PPP) projects for developing renewable energy infrastructure and facilities (Liu et al., 2018) provide guidelines for investors and policy makers in Australia.

III. The renewable energy generation maps illustrate that some renewable energy infrastructure is a significant distance from their market place, thus increasing the supply cost. In order to overcome this barrier, energy supply infrastructure must be well-planned and managed to improve the competitiveness of renewable energy, during and after infrastructure investment.

IV. Although renewable energy technology makes the utilisation of renewable energy feasible, technological advancement alone is not adequate to promote its broad utilisation (Romanach et al., 2015). Consequently, Australia's RET and FiTs play important roles. In particular, the TV FiTs offer the potential to alter consumer attitudes toward power usage at peak times, thereby improving grid security. However, customers' willingness to participate in the TV FiTs, and the influence of the TV FiT on the energy supply and customers are yet to be studied. Furthermore, despite being an important economic incentive for solar PV installations, the rate of FiTs is inconsistent from time to time, and from region to region, and the payback period in some regions/cities is excessive. Consistent and reasonable government support for renewable energy sources is expected to underpin a significant expansion in renewable energy over the coming decades, which will secure a more competitive, reliable and sustainable energy supply in Australia. 


\section{Conclusion}

Currently, $94 \%$ of Australia's total energy consumption is derived from fossil-based sources. This makes Australia the highest emitter of greenhouse gases per capita of any nation globally. In addressing this issue and fulfilling its environmental obligations, Australia is at a crucial stage of the transition to renewable energy adoption. The synthesis of literature presented in this research reveals that Australia is renowned for having favourable geophysical conditions for widely distributed renewable energy sources. Hydropower is one of the most well-developed renewable energy sources in Australia since early infratrusture development in the $19^{\text {th }}$ century. With an installed capacity of 8,790 MW, hydropower remains the largest renewable source of electrical energy generation in Australia, and the country is the world's fourth largest producer of hydropower. Australia also has the world's largest ocean renewable energy potential, contributing up to $11 \%$ of Australian's total energy needs by 2050 . Australia also has vast solar energy potential with approximately 58 million PJ of solar radiation being emitted on Australia annually. Another mature technology, wind energy, is the fastest growing renewable energy source given Australia's vast coastal regions. It is predicted that wind will be one of the least costly energy generation technologies in the nation by 2020 . Australia also has the potential to use geothermal energy, and the identified geothermal resources were estimated to be nearly 2.6 million PJ. The utilisation of geothermal energy in Australia is still in its infancy, with a noticeable lack of research investigation into its potential. Australia has more than 75 million tonnes (Mt) of biomass residues and waste material available annually derived from forest plantations, agricultural residues, and organic wastes, which can be used as the source of bioenergy. It is estimated that biofuels could reduce Australia's petrol consumption by as much as $10 \%$ to $140 \%$ of 2006 requirements depending upon the feedstock. Moreover, approximately $23 \mathrm{Mt}$ of municipal waste is deposited in landfills each year in Australia, making waste a viable source with significant potential for contributing to renewable energy production, as well as deviating waste from landfills.

Although the renewable energy source is Australia is diverse and ample, the wider utilisation renewable energy must be promoted.

Promoting the utilisation of renewable energy requires a consolidated socio-political effort to stimulate demand public for renewable energy adoption. That is, to grow this demand to reach beyond 
altruistic early adopters (who are often committed environmentalists) into the mainstream public, will require further alignment between innovative technological development and socioeconomic improvements. Clean and affordable energy production must be the unique selling point over and above any other cause related marketing related to the wider environmental impact - people must see the monetary value. Additionally, government policy incentives and a longer-term strategic plan of sustained investment into technological advancements are required to ensure that future renewable energy production solutions attract a triumvirate of future science, technology and manufacturing innovators. Working in a cross disciplinary fashion and from 'concept to final product' to harness Australia's abundant renewable resources will ensure that optimised renewable technological solutions are developed and utilised. Current developments have already engendered wider interest that is set to increase further, driving down costs of research, design and manufacture and hence, energy production. Creating a marketplace that is conducive to renewable energy power production will secure the sustainable growth of renewable energy utilisation in Australia with renewable energy becoming the dominant energy source of the future. Ultimately, there is no foreseeable, nor viable alternatives to the inevitable low carbon economy and so the evidence presented in this paper should be used to inform political machinations and effectuate an exponential transformation of the publicpolitical discourse to one that has renewables central to debate. To realise this requires a coalescence of science/ technology development, political will and public demand in equal measure.

Although these items have been mentioned in previous reports and studies on the topic, the research presented in this paper is unique in several ways. The study presents a positional perspective of Australia's current renewable energy market and provides a reliable benchmark source for making comparisons with findings in previously available review studies to assess advancements made. In addition, the research is one of the first to examine the TV FiT, a system that (although current figures show little positive variation in power use) promises significant rewards in the future. Furthermore, the current findings are extracted from the most recent academic publications alongside industry reports and industry publications in order to anchor the findings to the realities of contemporary developments in the field. Moreover, the present study highlights several areas that are currently overlooked in the literature. Of these, the crucial role of waste-to-energy potential for integration with 
other sources, and the need for adopting PPP projects in buildings facilities, operating and supervising waste-to-energy facilities, are areas in need of particular attention, and are largely ignored in the literature from the Australian context. The study's findings, however, remain in some instances conceptual, mainly due to a notable dearth of reliable data that prevents a more meaningful analysis of Australia's current renewable energy market to be explored in further depth. This provides fertile ground for future research. There are also some limitations of the research, most notably around the use of an interpretivist methodological design that is open to individual researcher bias. This risk was balanced through using validated data within extant literature but nevertheless, further work is required to assess government and public perceptions of renewable energy adoption as well as report upon the barriers and enablers to such.

\section{References}

ABC, 2018. SIMEC Zen Energy to build world's biggest battery near Port Augusta, overtaking Elon Musk's facility. https://www.abc.net.au/news/2018-03-16/worlds-biggest-battery-to-be-built-nearport-augusta/9554416. (Accessed 23 January 2019).

AEMO, 2018. 2018 Integrated System Plan. https://www.aemo.com.au/Media-Centre/2018Integrated-System-Plan. (Accessed 23 January 2019).

AER, 2017. AER Annual Report 2016-17. https://www.aer.gov.au/publications/corporatedocuments/aer-annual-report-2016-17. (Accessed 20 June 2018).

ARENA, 2019. Geothermal. https://arena.gov.au/where-we-invest/geothermal/. (Accessed 28 April 2019).

Australian Energy Council, 2018. Solar Report Quarter 1, 2018 Australian Energy Council,, Melbourne, Australia.

Australian Government, 2015. Australia's 2030 climate change target. http://www.environment.gov.au/climate-change/publications/factsheet-australias-2030-climatechange-target. (Accessed 30 April 2018).

Bahadori, A., Nwaoha, C., 2013. A review on solar energy utilisation in Australia. Renewable and Sustainable Energy Reviews 18, 1-5.

Bahadori, A., Nwaoha, C., Zendehboudi, S., Zahedi, G., 2013a. An overview of renewable energy potential and utilisation in Australia. Renewable and Sustainable Energy Reviews 21, 582-589.

Bahadori, A., Zahedi, G., Zendehboudi, S., 2013b. An overview of Australia's hydropower energy: Status and future prospects. Renewable and Sustainable Energy Reviews 20, 565-569.

Bahadori, A., Zendehboudi, S., Zahedi, G., 2013c. A review of geothermal energy resources in Australia: current status and prospects. Renewable and Sustainable Energy Reviews 21(0), 29-34. 
Baldwin, K., 2017. Renewables will be cheaper than coal in the future. Here are the numbers. http://theconversation.com/renewables-will-be-cheaper-than-coal-in-the-future-here-are-the-numbers84433. (Accessed 25 July 2018).

Behrens, S., Griffin, D., Hayward, J., Hemer, M., Knight, C., McGarry, S., Osman, P., Wright, J., 2012. Ocean renewable energy: 2015-2050. An analysis of ocean energy in Australia. https://doi.org/10.4225/08/584af1865b172. (Accessed 2 July 2018).

Berrada, A., Loudiyi, K., 2016. Operation, sizing, and economic evaluation of storage for solar and wind power plants. Renewable and sustainable energy Reviews 59, 1117-1129.

Bilgili, M., Ozbek, A., Sahin, B., Kahraman, A., 2015. An overview of renewable electric power capacity and progress in new technologies in the world. Renewable and Sustainable Energy Reviews $49,323-334$.

Bioenergy Australia, 2018. About Bioenergy. https://www.bioenergyaustralia.org.au/about/. (Accessed 30 July 2018).

Bloch, M., 2017. More Steps Towards 100\% Renewables In Yackandandah. https://www.solarquotes.com.au/blog/yackandandah-solar-power-mb0198/. (Accessed 23 January 2019).

Brakels, R., 2018. Victoria's New Time Varying Solar Feed-In Tariff Is Worth Getting. https://www.solarquotes.com.au/blog/victoria-time-varying-solar-tariff/. (Accessed 28 April 2019).

Brown, A., Landolina, S., Masanet, E., Sung, J., 2016. The Clean Energy Technology Assessment Methodology. International Energy Agency, Paris, France.

Brown, M., Cowie, A., 2014. Bioenergy: Australia's forgotten renewable energy source (so far) http://theconversation.com/bioenergy-australias-forgotten-renewable-energy-source-so-far-28277. (Accessed 30 July 2018).

Bureau of Meteorology, 2016. Average daily solar exposure. http://www.bom.gov.au/jsp/ncc/climate averages/solar-exposure/index.jsp. (Accessed 25 July 2018).

Burke, M., Davis, W.M., Diffenbaugh, N.S., 2018. Large potential reduction in economic damages under UN mitigation targets. Nature 557(7706), 549-553.

Byrnes, L., Brown, C., Foster, J., Wagner, L.D., 2013. Australian renewable energy policy: Barriers and challenges. Renewable Energy 60, 711-721.

Carbajo, R., Cabeza, L.F., 2018. Renewable energy research and technologies through responsible research and innovation looking glass: reflexions, theoretical approaches and contemporary discourses. Applied Energy 211, 792-808.

Castilla-Polo, F., Ruiz-Rodríguez, C., 2017. Content analysis within intangible assets disclosure: a structured literature review. Journal of Intellectual Capital 18(3), 506-543.

CCA, 2019. Review of the National Greenhouse and Energy Reporting legislation - final report. http://climatechangeauthority.gov.au/review-national-greenhouse-and-energy-reporting-legislationfinal-report. (Accessed 23 January 2019).

CEFC, 2015. The Australian bioenergy and energy from waste market. https://www.cefc.com.au/media/203028/the-australian-bioenergy-and-energy-from-waste-marketcefc-market-report.pdf. (Accessed 16 August 2018). 
CEFC, 2016. Energy from waste in Australia: a state-by-state update. https://www.cefc.com.au/.../cefc-energy-from-waste-market-report-november-2016.pdf. (Accessed 16 August 2018).

Chapman, A.J., McLellan, B., Tezuka, T., 2016. Residential solar PV policy: An analysis of impacts, successes and failures in the Australian case. Renewable Energy 86, 1265-1279.

Chapman, A.J., McLellan, B.C., Tezuka, T., 2018. Prioritizing mitigation efforts considering cobenefits, equity and energy justice: Fossil fuel to renewable energy transition pathways. Applied Energy 219, 187-198.

Chu, T., 2018. Rethinking the role of hydropower in Australia. http://www.entura.com.au/rethinkingthe-role-of-hydropower-in-australia/. (Accessed 23 January 2019).

Clean Energy Council, 2014. Renewable energy map. https://www.cleanenergycouncil.org.au/technologies/renewable-energy-map.html. (Accessed 20 June 2018).

Clean Energy Council, 2017 Renewable Energy Target. https://www.cleanenergycouncil.org.au/policy-advocacy/renewable-energy-target.html. (Accessed 31 July 2018).

Clean Energy Council, 2018 Clean Energy Australia Report. https://www.cleanenergycouncil.org.au/policy-advocacy/reports/clean-energy-australia-report.html. (Accessed 4 July 2018).

Clean Energy Regulator, 2018. The renewable power percentage. http://www.cleanenergyregulator.gov.au/RET/Scheme-participants-and-industry/the-renewablepower-percentage. (Accessed 23 January 2019).

Cludius, J., Forrest, S., MacGill, I., 2014. Distributional effects of the Australian Renewable Energy Target (RET) through wholesale and retail electricity price impacts. Energy Policy 71, 40-51.

Court, S.H.à., 2017. How many Australian coal fired power stations have been shut down since 2012? https://www.quora.com/How-many-Australian-coal-fired-power-stations-have-been-shut-down-since2012. (Accessed 20 June 2018).

Crawford, R.H., Treloar, G.J., 2004. Net energy analysis of solar and conventional domestic hot water systems in Melbourne, Australia. Solar Energy 76(1), 159-163.

D'Souza, C., Yiridoe, E.K., 2014. Social acceptance of wind energy development and planning in rural communities of Australia: A consumer analysis. Energy Policy 74, 262-270.

DEE, 2018. Australian Energy Statistics. https://www.energy.gov.au/government-priorities/energydata/australian-energy-statistics. (Accessed 20 August 2019).

Dincer, F., 2011. The analysis on photovoltaic electricity generation status, potential and policies of the leading countries in solar energy. Renewable and Sustainable Energy Reviews 15(1), 713-720.

Ekpenyong, E.J., Okonnah, M.I., John, E.D., 2008. Polynomial (Non Linear) Regression Method for Improved Estimation Based on Sampling. Journal of Applied Sciences 8(8), 1597-1599.

Elliston, B., Riesz, J., MacGill, I., 2016. What cost for more renewables? The incremental cost of renewable generation - An Australian National Electricity Market case study. Renewable Energy 95, 127-139. 
Energy Matters, 2018. Information on Australian Solar Feed-In Tariffs. https://www.energymatters.com.au/rebates-incentives/feedintariff/\#fit-table. (Accessed 1 August 2018).

European Commission, 2018. 2030 Energy Strategy https://ec.europa.eu/energy/en/topics/energystrategy-and-energy-union/2030-energy-strategy. (Accessed 20 June 2018).

Evans, J.P., Kay, M., Prasad, A., Pitman, A., 2018. The resilience of Australian wind energy to climate change. Environmental Research Letters 13(2), 024014.

Gartry, L., 2018. Tidal power trial shows promise for new wave of renewable energy development. https://www.abc.net.au/news/2018-11-23/tidal-power-new-wave-renewable-energy-developmentqueensland/10544862. (Accessed 23 January 2019).

Geoscience Australia, 2018a. Bio. http://aera.ga.gov.au/\#!/bio. (Accessed 4 July 2018).

Geoscience Australia, 2018b. Geothermal Energy Resources. http://www.ga.gov.au/scientifictopics/energy/resources/geothermal-energy-resources. (Accessed 23 January 2019).

Geoscience Australia, 2018c. Hydro. http://aera.ga.gov.au/\#!/hydro. (Accessed 30 July 2018).

Geoscience Australia, 2018d. Ocean. http://aera.ga.gov.au/\#!/ocean. (Accessed 30 July 2018).

Geoscience Australia, 2018e. Solar. http://aera.ga.gov.au/\#!/solar. (Accessed 4 July 2018).

Geoscience Australia, 2018f. Wind. http://aera.ga.gov.au/\#!/wind. (Accessed 4 July 2018).

Goddard, G., Farrelly, M.A., 2018. Just transition management: Balancing just outcomes with just processes in Australian renewable energy transitions. Applied Energy 225, 110-123.

Goh, T., Ang, B.W., Su, B., Wang, H., 2018. Drivers of stagnating global carbon intensity of electricity and the way forward. Energy Policy 113, 149-156.

Hallgren, W., Gunturu, U.B., Schlosser, A., 2014. The potential wind power resource in Australia: A new perspective. PloS one 9(7), e99608.

Hamawand, I., Yusaf, T., Hamawand, S.G., 2013. Coal seam gas and associated water: A review paper. Renewable and Sustainable Energy Reviews 22, 550-560.

Harrell, F.E., 2015. Regression Modeling Strategies: With Applications to Linear Models, Logistic and Ordinal Regression, and Survival Analysis. Springer International Publishing.

Hemer, M., Pitman, T., McInnes, K., Rosebrock, U., 2018. The Australian Wave Energy Atlas Project Overview and Final Report. CSIRO Oceans and Atmosphere, Australia.

Hemer, M.A., Manasseh, R., McInnes, K.L., Penesis, I., Pitman, T., 2018. Perspectives on a way forward for ocean renewable energy in Australia. Renewable Energy 127, 733-745.

Hemer, M.A., Zieger, S., Durrant, T., O'Grady, J., Hoeke, R.K., McInnes, K.L., Rosebrock, U., 2017. A revised assessment of Australia's national wave energy resource. Renewable Energy 114, 85-107.

Herr, A., Dunlop, M., 2011. Bioenergy in Australia: An improved approach for estimating spatial availability of biomass resources in the agricultural production zones. Biomass and Bioenergy 35(5), 2298-2305. 
Hla, S.S., Lopes, R., Roberts, D., 2016. The CO2 gasification reactivity of chars produced from Australian municipal solid waste. Fuel 185, 847-854.

Hla, S.S., Roberts, D., 2015. Characterisation of chemical composition and energy content of green waste and municipal solid waste from Greater Brisbane, Australia. Waste Management 41, 12-19.

Hoicka, C.E., Rowlands, I.H., 2011. Solar and wind resource complementarity: Advancing options for renewable electricity integration in Ontario, Canada. Renewable Energy 36(1), 97-107.

Howard, B.S., Hamilton, N.E., Diesendorf, M., Wiedmann, T., 2018. Modeling the carbon budget of the Australian electricity sector's transition to renewable energy. Renewable Energy 125, 712-728.

Hua, Y., Oliphant, M., Hu, E.J., 2016. Development of renewable energy in Australia and China: A comparison of policies and status. Renewable Energy 85, 1044-1051.

IHA, 2017. hydropower status report. https:/www.hydroworld.com/content/dam/hydroworld/onlinearticles/2017/08/2017\%20Hydropower\%20Status\%20Report-1.pdf. (Accessed 23 January 2019).

Jacobsson, S., Johnson, A., 2000. The diffusion of renewable energy technology: an analytical framework and key issues for research. Energy Policy 28(9), 625-640.

Jordaan, S.M., Romo-Rabago, E., McLeary, R., Reidy, L., Nazari, J., Herremans, I.M., 2017. The role of energy technology innovation in reducing greenhouse gas emissions: A case study of Canada. Renewable and Sustainable Energy Reviews 78, 1397-1409.

Kaldellis, J.K., Zafirakis, D., 2011. The wind energy (r) evolution: A short review of a long history. Renewable Energy 36(7), 1887-1901.

Kazem, H.A., 2011. Renewable energy in Oman: Status and future prospects. Renewable and Sustainable Energy Reviews 15(8), 3465-3469.

KPMG, 2015. Taxes and incentives for renewable energy. http://www.kpmg.com/energytax. (Accessed 1 Auguest 2018).

Lesser, J.A., Su, X., 2008. Design of an economically efficient feed-in tariff structure for renewable energy development. Energy Policy 36(3), 981-990.

Liu, Y., Sun, C., Xia, B., Liu, S., Skitmore, M., 2018. Identification of Risk Factors Affecting PPP Waste-to-Energy Incineration Projects in China: A Multiple Case Study. Advances in Civil Engineering 2018, 1-16.

Lowe, I., 2012. Rethink RET, and the Clean Energy Finance Corp could kick off a new industrial revolution. http://theconversation.com/rethink-ret-and-the-clean-energy-finance-corp-could-kick-offa-new-industrial-revolution-7769. (Accessed 31 July 2018).

Manasseh, R., McInnes, K.L., Hemer, M.A., 2017. Pioneering developments of marine renewable energy in Australia. The International Journal of Ocean and Climate Systems 8(1), 50-67.

Martek, I., Hosseini, M.R., Shrestha, A., Edwards, D.J., Durdyev, S., 2019. Barriers inhibiting the transition to sustainability within the Australian construction industry: An investigation of technical and social interactions. Journal of Cleaner Production 211, 281-292.

Martek, I., Hosseini, M.R., Shrestha, A., Zavadskas, E.K., Seaton, S., 2018. The sustainability narrative in contemporary architecture: Falling short of building a sustainable future. Sustainability 10(981). 
Masini, A., Menichetti, E., 2012. The impact of behavioural factors in the renewable energy investment decision making process: Conceptual framework and empirical findings. Energy Policy 40, $28-38$

McDonagh, S., O'Shea, R., Wall, D.M., Deane, J., Murphy, J.D., 2018. Modelling of a power-to-gas system to predict the levelised cost of energy of an advanced renewable gaseous transport fuel. Applied Energy 215, 444-456.

Mey, F., Diesendorf, M., MacGill, I., 2016. Can local government play a greater role for community renewable energy? A case study from Australia. Energy Research \& Social Science 21, 33-43.

Mölder, B., 2010. Mind Ascribed: An elaboration and defence of interpretivism (Advances in Consciousness Research). John Benjamins Publishing, London.

Montgomery, D.C., Peck, E.A., Vining, G.G., 2012. Introduction to linear regression analysis. John Wiley \& Sons.

Musa, S.D., Zhonghua, T., Ibrahim, A.O., Habib, M., 2018. China's energy status: A critical look at fossils and renewable options. Renewable and Sustainable Energy Reviews 81, 2281-2290.

Myers, M.D., 2013. Qualitative research in business and management. Sage Publications Ltd, London.

Ndevr, 2018. Tracking 2 Degrees - FY18 Q1. http://ndevr.com.au/environmental/tracking-2-degreesfy18-q1. (Accessed 23 January 2019).

Ndevr, 2019. Tracking 2 Degrees - FY19 Q1. http://ndevr.com.au/environmental/tracking-2-degreesfy19-q1. (Accessed 23 January 2019).

Nelson, T., Simshauser, P., Nelson, J., 2012. Queensland solar feed-in tariffs and the merit-order effect: Economic benefit, or regressive taxationand wealth transfers? Economic Analysis and Policy 42(3), 277.

Office of the Chief Economist, 2016. Resources and Energy Quarterly - December 2016. https://www.industry.gov.au/data-and-publications/resources-and-energy-quarterly-december-2016. (Accessed 25 July 2018).

Olatomiwa, L., Mekhilef, S., Ismail, M.S., Moghavvemi, M., 2016. Energy management strategies in hybrid renewable energy systems: A review. Renewable and Sustainable Energy Reviews 62, 821-835.

Pant, A., 2019. Introduction to Linear Regression and Polynomial Regression. https://towardsdatascience.com/introduction-to-linear-regression-and-polynomial-regressionf8adc96f31cb. (Accessed 20 August 2019).

Petersen, J.-P., 2018. The application of municipal renewable energy policies at community level in Denmark: A taxonomy of implementation challenges. Sustainable Cities and Society.

Poruschi, L., Ambrey, C.L., Smart, J.C.R., 2018. Revisiting feed-in tariffs in Australia: A review. Renewable and Sustainable Energy Reviews 82, 260-270.

Prasad, A.A., Taylor, R.A., Kay, M., 2017. Assessment of solar and wind resource synergy in Australia. Applied Energy 190, 354-367.

Puri, M., Abraham, R.E., Barrow, C.J., 2012. Biofuel production: Prospects, challenges and feedstock in Australia. Renewable and Sustainable Energy Reviews 16(8), 6022-6031. 
Queensland Competition Authority, 2018. Time-varying solar price for 2018-19. http://www.qca.org.au/Electricity/Regional-consumers/ministerial-advice/Final-Report/Advice-toGovernment-time-varying-solar-price-fo. (Accessed 28 April 2019).

Queensland Government, 2018. Feed-in tariffs for regional Queensland. https://www.qld.gov.au/housing/buying-owning-home/energy-water-home/solar/feed-in-tariffs/feedin-tariff-regional-queensland. (Accessed 28 April 2019).

Rahman, K.M., Melville, L., Edwards, D.J. and El-Gohary, H. (2019a) Implementation of Bioenergy Systems towards Achieving United Nations' Sustainable Development Goals in rural Bangladesh. Sustainability. 11(14). DOI: https://doi.org/10.3390/su11143814.

Rahman, K.M., Melville, L., Edwards, D.J. and Thawla, D.W. (2019b) Determination of the Potential impact of domestic Anaerobic Digester Systems: A Community based Research Initiative in Rural Bangladesh. Processes. 7(8), pp. 512. DOI: https://doi.org/10.3390/pr7080512

Raison, R.J., 2006. Opportunities and impediments to the expansion of forest bioenergy in Australia. Biomass and Bioenergy 30(12), 1021-1024.

Rajesh, R., Carolin Mabel, M., 2015. A comprehensive review of photovoltaic systems. Renewable and Sustainable Energy Reviews 51, 231-248.

Reim, W., Parida, V., Örtqvist, D., 2015. Product-Service Systems (PSS) business models and tactics - a systematic literature review. Journal of Cleaner Production 97, 61-75.

Robert, F.C., Sisodia, G.S., Gopalan, S., 2018. A critical review on the utilization of storage and demand response for the implementation of renewable energy microgrids. Sustainable cities and society.

Román-Leshkov, Y., Barrett, C.J., Liu, Z.Y., Dumesic, J.A., 2007. Production of dimethylfuran for liquid fuels from biomass-derived carbohydrates. Nature 447(7147), 982.

Romanach, L., Carr-Cornish, S., Muriuki, G., 2015. Societal acceptance of an emerging energy technology: How is geothermal energy portrayed in Australian media? Renewable and Sustainable Energy Reviews 42, 1143-1150.

Siégel, C., Schrank, C.E., Bryan, S.E., Beardsmore, G.R., Purdy, D.J., 2014. Heat-producing crust regulation of subsurface temperatures: A stochastic model re-evaluation of the geothermal potential in southwestern Queensland, Australia. Geothermics 51, 182-200.

Simpson, G., Clifton, J., 2016. Subsidies for residential solar photovoltaic energy systems in Western Australia: Distributional, procedural and outcome justice. Renewable and Sustainable Energy Reviews 65, 262-273.

Slaughter, E.S., 2000. Implementation of construction innovations. Building research \& information 28(1), 2-17.

Solar Choice, 2018. NSW solar feed-in tariff rates to drop from 1 July 2018: What does it all mean? https://www.solarchoice.net.au/blog/nsw-solar-feed-in-tariff-rates-to-drop-from-1-july-2018/.

(Accessed 28 April 2019).

Sommerfeld, J., Buys, L., Vine, D., 2017. Residential consumers' experiences in the adoption and use of solar PV. Energy Policy 105, 10-16. 
Stoppato, A., 2008. Life cycle assessment of photovoltaic electricity generation. Energy 33(2), 224232.

Teske, S., Dominish, E., Ison, N., Maras, K., 2016. 100\% Renewable Energy for Australia Decarbonising Australia's Energy Sector within one Generation. Institute for Sustainable Futures, University of Technology Sydney, Sydney.

The World Bank Group, 2016. Global Solar Atlas. http://globalsolaratlas.info/?c=59.800634,64.6875,2. (Accessed 25 July 2018).

Trainer, T., 2012. Can Australia run on renewable energy? The negative case. Energy Policy 50, 306314.

Tran, T.T.D., Smith, A.D., 2017. Evaluation of renewable energy technologies and their potential for technical integration and cost-effective use within the U.S. energy sector. Renewable and Sustainable Energy Reviews 80, 1372-1388.

Vieira, F.M., Moura, P.S., de Almeida, A.T., 2017. Energy storage system for self-consumption of photovoltaic energy in residential zero energy buildings. Renewable Energy 103, 308-320.

Wüstenhagen, R., Wolsink, M., Bürer, M.J., 2007. Social acceptance of renewable energy innovation: An introduction to the concept. Energy Policy 35(5), 2683-2691.

Yusaf, T., Goh, S., Borserio, J., 2011. Potential of renewable energy alternatives in Australia. Renewable and sustainable energy reviews 15(5), 2214-2221.

Zhang, X., Li, H.-Y., Deng, Z.D., Ringler, C., Gao, Y., Hejazi, M.I., Leung, L.R., 2017. Impacts of climate change, policy and Water-Energy-Food nexus on hydropower development. Renewable Energy. 